\title{
0 Aglomerado de Empresas Atuantes no Segmento Off-Shore de Macaé: impactos da política de subcontratação da Petrobras na bacia de Campos*
}

\author{
Roberto Cezar Rosendo Saraiva da Silva
}

Universidade Estadual do Norte Fluminense

Jorge Britto

Universidade Federal Fluminense

Recebido: 6/7/2007 Aprovado: 9/5/2008

\section{Resumo}

A bacia de Campos (BC) é responsável pela produção de $84 \%$ do petróleo e de $45 \%$ do gás natural brasileiros. Nas últimas décadas, o município de Macaé - base operacional da BC - presenciou o desenvolvimento de um aglomerado de empresas especializadas em atividades off-shore. $\mathrm{O}$ artigo busca caracterizar esse aglomerado, destacando sua organização industrial, as relaçôes interfirmas e a infraestrutura de ciência e tecnologia. Particular importância é atribuída à evolução recente da política de subcontratação da Petrobras, implementada a partir de 2003, enfatizando-se como essa política tem redefinido, de forma substancial, os vínculos produtivos no arranjo, especialmente com respeito às pequenas e médias empresas (PMEs), provocando impactos relevantes na dinâmica produtiva e tecnológica do aglomerado. A pesquisa realizada sugere que as mudanças recentes na política de subcontratação da Petrobras têm induzido o aumento da cooperação técnico-produtiva no aglomerado, ao mesmo tempo em que reforçam uma tendência à aceleração do processo de concentração industrial, gerando impactos em termos da ameaça de exclusão de PMEs que integram o aglomerado.

Palavras-Chave | Aglomerado Petrolífero de Macaé; Política de Subcontratação da Petrobras, Bacia de Campos

Códigos JEL | L22; O17

* Os autores agradecem os comentários dos pareceristas anônimos que contribuíram decisivamente para a correção de imprecisões na versão final do artigo. Aquelas remanescentes são de inteira responsabilidade dos autores. 


\section{Abstract}

Campos' basin is responsible for $84 \%$ of the petroleum and for $45 \%$ of the natural gas produced in Brazil. The district of Macaé, located in the epicenter of the basin, has become a robust cluster of specialized companies in off-shore activities. The paper analyzes that cluster, emphasizing: its industrial organization, inter-firms relationships and the local infrastructure of science and technology. Particular attention is given to changes in Petrobras subcontracting policy implemented since 2003 and to the discussion of how these changes have impacted the dynamics of the cluster; especially with respect to small and medium enterprises (SMEs). The research indicates that the policy of Petrobras has induced the increase of technological and productive cooperation, as well as the acceleration of the process of industrial concentration, with potential impacts in terms of the exclusion of SMEs.

Keywords | Off-Shore Cluster; Petrobras Subcontracting Policy; Campos Basin

JEL-Codes | L22; O17

\section{Introdução}

Segundo a Agência Nacional de Petróleo (ANP), ${ }^{1}$ no ano de 2005, a bacia de Campos (BC) foi responsável pela produção de $84,1 \%$ do petróleo brasileiro, detendo $80 \%$ das reservas provadas do país. No tocante ao gás natural, a província petrolífera concentrou a produção de $45 \%$ do volume total produzido, detendo 47,4\% das reservas provadas do país (ANP, 2007). A bacia de Campos possui cerca de 100 mil quilômetros quadrados, estendendo-se do Espírito Santo (próximo a Vitória) até Cabo Frio, no litoral norte do estado do Rio de Janeiro. Para viabilizar a produção de óleo e gás, a BC conta com 38 campos off-shore em operação. Nesses campos, são operados 1.814 poços de óleo e gás através de 37 plataformas fixas e móveis de produção, as quais se interligam através de 3.900 quilômetros de dutos submarinos (Petrobras, 2006).

1 Entidade integrante da administração federal indireta, submetida ao regime autárquico especial, instituída como órgão regulador da indústria do petróleo, vinculado ao Ministério de Minas e Energia através da Lei n. 9.478, de 6 de agosto de 1997 (Lei do Petróleo). 
O município de Macaé - localizado na região norte fluminense do estado do Rio de Janeiro - encontra-se no epicentro da maior província petrolífera do Brasil, consolidando-se como um robusto aglomerado de empresas especializadas em atividades petrolíferas off-shore e como a base das operações de produção de petróleo e gás da BC. Por sua vez, o crescimento da atividade industrial de Macaé resulta, por um lado, dos crescentes investimentos realizados em exploração, desenvolvimento e produção de petróleo e gás (E\&P) na bacia de Campos - em especial pela Petrobras - e, por outro, do ingresso de empresas atuantes no mercado off-shore (operadoras e fornecedoras de bens e serviços), muitas das quais estrangeiras, atraídas pelas oportunidades de negócios na BC. Esse processo foi acelerado em função da quebra do monopólio de exploração da Petrobras, a partir da Lei do Petróleo de 1997. Assim, em pouco mais de três décadas, Macaé presenciou a mudança de sua base produtiva, de uma estrutura tipicamente primária para uma estrutura industrial e de prestação de serviços. Segundo dados do IBGE, o PIB do município de Macaé cresceu $260 \%$ entre $1999-2003$ contra um valor de $14 \%$ para o conjunto do estado do Rio de Janeiro. Já o PIB industrial de Macaé cresceu 309\% contra 47\% do PIB industrial fluminense (Tabela 1).

A Organização Nacional da Indústria do Petróleo (ONIP) estima que os investimentos a serem realizados no Brasil até o ano de 2010, incluídas empresas fornecedoras de equipamentos e infraestrutura para setores de petróleo e gás, chegarão à casa dos US\$ 100 bilhôes. A Petrobras, maior operadora do país, previa investir US \$ 53,6 bilhões no período 2004-2010, nas diversas áreas em que atua. Desse total, US \$ 32,1 bilhôes seriam empregados em atividades de exploração, desenvolvimento e produção - E\&P, e a BC concentra a maior parcela desses recursos (Petrobras, 2006). Informaçôes mais atualizadas, relativas ao plano de negócios 2008-2012 previam investimentos da ordem de US\$ 112,4 bilhōes, os quais representavam uma média de US\$22,5 bilhōes por ano, o que representava um aumento de $29 \%$ em relação ao plano anterior (2007-2011).

O objetivo da análise desenvolvida é caracterizar o Aglomerado Petrolífero de Macaé (APM), avaliando os impactos da política de contratação e subcontratação da Petrobras-bacia de Campos, especialmente sobre o processo de cooperação técnicoprodutiva que envolve as empresas atuantes no aglomerado. $\mathrm{Na}$ última década, esse aglomerado experimentou uma forte expansão, em paralelo à consolidação de um modelo de organização industrial crescentemente concentrado, que se aproxima do formato centrorradial proposto na análise de Markusen (1999). No centro do sistema produtivo, encontra-se a Petrobras, principal empresa do arranjo, responsável pela 
TABELA 1

Crescimento do PIB e do produto industrial 1999-2003

Macaé e estado do Rio de Janeiro - Valores correntes

\begin{tabular}{lcccccc}
\hline & 1999 & 2000 & 2001 & 2002 & 2003 & Var. 1999-2003 \\
$\begin{array}{l}\text { Macaé - } \\
\text { PIB total }\end{array}$ & 2.934 .554 & 4.889 .127 & 5.829 .536 & 7.840 .777 & 10.581 .549 & $260,6 \%$ \\
$\begin{array}{l}\text { Macaé - } \\
\text { PIB industrial }\end{array}$ & 2.324 .602 & 4.140 .452 & 4.859 .675 & 8.931 .458 & 9.512 .654 & $309,2 \%$ \\
$\begin{array}{l}\text { Rio de Janeiro - } \\
\text { PIB total }\end{array}$ & 123.982 .585 & 137.876 .531 & 137.277 .282 & 143.244 .257 & 142.150 .970 & $14,7 \%$ \\
& & & & & & \\
$\begin{array}{l}\text { Rio de Janeiro }- \\
\text { PIB industrial }\end{array}$ & 48.486 .737 & 59.498 .827 & 60.397 .435 & 68.452 .882 & 71.528 .105 & $47,5 \%$
\end{tabular}

Fonte: Anuário estatístico do estado do Rio de Janeiro, 2000-2004

maior parcela da demanda de bens e serviços relacionados ao desenvolvimento das atividades de exploração, desenvolvimento e produção de óleo e gás na BC. No entorno da Petrobras estão respectivamente as grandes empresas off-shore, na grande maioria multinacionais, voltadas para a prestação de serviços altamente especializados, empresas nacionais de engenharia que operam como EPCistas e as pequenas e médias empresas (PMEs), majoritariamente nacionais, que atuam no aglomerado basicamente como subcontratadas.

Em estudos sobre aglomerações produtivas que apresentam um formato similar, verifica-se, de forma recorrente, um elevado grau de assimetria entre a empresa central e as empresas radiais. Dessa forma, mudanças no processo produtivo da empresa central tendem a exercer impactos expressivos nas demais empresas do sistema, determinando processos de concentração e reconcentração industrial que podem influenciar a evolução do aglomerado no longo prazo. No caso de aglomeraçôes produtivas em regiôes e localidades de baixo desenvolvimento, como é o caso de Macaé, processos que levam à concentração industrial afetam, sobretudo, a sobrevivência das PMEs, que, em geral, têm expressiva participação na geração de emprego e renda daquelas localidades.

A hipótese do trabalho é que a política de subcontratação ${ }^{2}$ adotada pela Petrobras-BC tende a reforçar a verticalização de estrutura produtiva do APM,

2 Emprega-se o termo "política de subcontratação da Petrobras" para indicar que a estatal define os parâmetros para a compra de bens e serviços tanto para as empresas diretamente "contratadas", em geral dotadas de maior aporte financeiro e tecnológico, quanto para as empresas "subcontratadas", em grande parte PMEs, mais numerosas e responsáveis por parcela considerável dos empregos no aglomerado. 
privilegiando articulações com grandes empresas atuantes no segmento off-shore e afetando, sobretudo, a expansão, a diversificação produtiva e o avanço tecnológico das PMEs que atuam no aglomerado. Dada a importância da indústria petrolífera na dinâmica socioeconômica de Macaé, há indícios de que a aceleração do processo de concentração industrial pode vir a restringir a estruturação de uma rede de firmas mais capilarizada e a reforçar a assimetria da estrutura industrial do APM, restringindo as possibilidades de aprofundamento dos processos de cooperação interfirmas e determinando impactos potencialmente negativos no que tange à inovação, diversificação e sustentabilidade do sistema produtivo local.

$\mathrm{O}$ artigo é desenvolvido ao longo de cinco seções, incluindo esta introdução. A seção 2 apresenta a base teórico-metodológica que orienta o esforço de investigação. Na seção 3 busca-se caracterizar o Aglomerado Petrolífero de Macaé, no que tange à sua organização produtiva e infraestrutura, com base em dados da Relação Anual de Informações Sociais (RAIS) do Ministério do Trabalho e Emprego (MTb). Na seção 4, discute-se a atual política de contratação da Petrobras Unidade Bacia de Campos e seus impactos no processo de cooperação técnico-produtiva, com destaque para as PMEs, a partir de tendências identificadas na literatura especializada e em evidências coletadas em pesquisa qualitativa, de caráter exploratório, realizada em empresas selecionadas do aglomerado. Por fim, a seção 5 é destinada às considerações finais.

\section{Fundamentos teóricos-conceituais}

A aglomeração espacial de atividades econômicas é uma temática para a qual confluem análises que se encontram na fronteira entre a literatura de organização industrial e os estudos de economia regional. A perspectiva metodológica dos estudos de organização industrial ressalta a importância de se identificar, com o maior nível de detalhe possível, qual a "estrutura" interna dessas aglomeraçóes, o que envolve uma série de questôes importantes, tais como o padrão de especialização setorial das delas, o tamanho relativo de seus membros participantes, as características das articulações interindustriais subjacentes, os impactos econômicos e as vantagens competitivas que podem ser geradas a partir da estruturação desses arranjos. Em comparação com esse tipo de recorte analítico, os estudos de economia regional costumam atribuir particular importância a determinados "fatores locacionais" que influenciam a instalação de uma indústria em determinada região, procurando explicitar as forças motoras desse processo e os impactos resultantes sobre a dinâmica de reprodução e transformação de regiôes geoeconômicas específicas. Dois aspectos específicos destacam-se como pontos 
de confluência e complementaridade entre essas abordagens. Por um lado, ambas ressaltam a importância da "proximidade" entre os agentes - a qual pode ser referenciada ao plano organizacional, espacial ou a diferentes estágios de determinada cadeia produtiva - como fator de indução de articulações e interações entre eles. Por outro, essas análises também ressaltam a importância do contexto social e institucional subjacente como fator de estímulo à consolidação dessas aglomerações. O Quadro 1 apresenta uma síntese das principais escolas de pensamento voltadas para a análise de aglomerações produtivas.

Ramos (1999:33) enumera cinco razões para a formação de aglomerações produtivas, que sintetizam as escolas de pensamento mencionadas no Quadro 1:

1) a concentração de empresas em uma região atrai mais clientes, ampliando o mercado muito além do que ocorreria se as empresas estivessem operando isoladamente;

2) a criação de competências resultantes dessa concentração de empresas induz uma maior especialização, divisão do trabalho e, consequentemente, maior produtividade;

3) a forte interação entre produtores, provedores e usuários facilita e induz aprendizado produtivo, tecnológico e de comercialização;

4) as repetidas transações realizadas localmente entre os mesmos agentes econômicos geram maior confiança e reputação, o que resulta em menores custos de transação;

5) o estabelecimento de articulações sistemáticas entre agentes facilita a ação coletiva em prol de metas comuns, tais como a expansão internacional, a coordenação dos esforços de capacitação, a montagem de centros de pesquisa e desenvolvimento ( $\mathrm{P} \& \mathrm{D})$, a compatibilização de normas de qualidade e padrões técnicos, dentre outras.

A partir desse panorama geral, é possível avançar no sentido da identificação de um quadro de referência teórico-conceitual que seja funcional em relação aos objetivos da investigação proposta. Nesse sentido, do ponto de vista teórico-conceitual a análise realizada a seguir procurou utilizar dois recortes complementares para analisar o processo de cooperação técnico-produtiva no âmbito do APM, relacionados respectivamente à noção de Arranjos Produtivos e Sistemas Inovativos Locais (Lastres \& Cassiolato, 2003) e ao enfoque que privilegia a análise do modus operandi das redes de firmas, conforme proposto por Britto (1999). 


\section{QUADRO 1}

\section{Sumário de abordagens teóricas sobre aglomerações produtivas}

\section{Abordagens \\ teóricas}

Nova Geografia Econômica (P. Krugman, 1998): elaborada a partir das contribuições pioneiras de Alfred Marshall. Aglomerações resultam de causação cumulativa induzida pela presença de economias externas locais. Economias externas são incidentais, e a estrutura espacial da economia é determinada pela operação de forças centrípetas e centrífugas.

Economia dos Negócios (M. Porter, 1989): destaca a importância de economias externas geograficamente restritas, enfatizando a importância da "concentração de habilidades e conhecimentos altamente especializados, instituições rivais, atividades correlatas e consumidores sofisticados" no fortalecimento da competitividade empresarial.

Economia Regional (A. Scott, 1998): geografia econômica e desempenho industrial estão interligados. Existe uma tendência endêmica do capitalismo se estruturar em densos aglomerados localizados. Esses aglomerados são constituídos como economias regionais intensivas em transação, que, por sua vez, apresentam relações de interdependência com os mercados "externos".

Economia da Inovação (D.B. Audretsch, 1998): a proximidade local facilita o fluxo de informação e efeitos spill-overs, que favorecem a disseminação de conhecimento. Atividades econômicas baseadas em novo conhecimento têm grande propensão a se aglomerar dentro de uma região geográfica.

Pequenas Empresas e Distritos Industriais (H. Schmitz, 1997-1999): além das economias externas locais incidentais ou espontâneas, existe também uma força deliberada em ação, decorrente de cooperação conscientemente buscada entre agentes privados e do apoio do setor público.

\section{Formação do aglomerado}

Aglomerados são resultado das forças de mercado.
Implicações normativas Papel do governo

Pouco espaço para a política econômica.
Aglomerados são resultado das forças de mercado. Estratégias locacionais são parte das estratégias de negócios.

\section{Coordenação}

extramercado.

\section{Coordenação}

extramercado.

\section{Decorre de ações do} mercado (não-planejadas) e de ações coletivas (planejadas).
O governo deve prover educação, infraestrutura física e regras de estímulo à concorrência.
Políticas públicas são essenciais na construção de vantagens competitivas localizadas.

\section{Políticas de} desregulamentação que permitam maior interação produtiva entre as empresas, no âmbito local e regional.

Políticas ativas visando ao aumento da cooperação no aglomerado e criação de infraestrutura. 
O enfoque de Arranjos Produtivos e Inovativos Locais - APLs - segue a linha do arcabouço teórico dos Sistemas Locais e Regionais de Inovação e tem sido aprimorado no sentido de incorporar as características de uma economia crescentemente "baseada no conhecimento" e as especificidades de aglomerados produtivos característicos de regiōes de baixo e médio níveis de desenvolvimento. Apesar da cooperação produtiva e/ou tecnológica não ser uma implicação necessária da consolidação desses arranjos, supõe-se que a estruturação destes estimula um processo de interação local que viabiliza o aumento da eficiência produtiva, criando um ambiente propício à elevação da competitividade dos agentes integrados ao arranjo. Em particular, esse tipo de recorte analítico enfatiza os impactos das articulações locais entre agentes em termos da geração de efeitos de aprendizado e da dinamização do processo inovativo em escala local ou regional. Lastres e Cassiolato (2003c:2) distinguem dois tipos de aglomeraçōes produtivas em economias periféricas:

1) aglomerados que detêm pouca ou nenhuma densidade em termos de suas articulações e interações produtivas e tecnológicas internas, tipificados como Arranjos Produtivos;

2) aglomerados que apresentam elementos característicos de um sistema de inovação mais bem-estruturado, denominados de Sistemas Produtivos e Inovativos Locais.

De modo a captar esses aspectos e a instrumentalizar a realização de análises empíricas baseadas naqueles conceitos, Lastres e Cassiolato (2003b:10-12) propõem o seguinte recorte metodológico para a análise de arranjos e sistemas produtivos locais:

“(i) caracterizar os arranjos produtivos locais, sua história, principais atividades econômicas, produtos, serviços, firmas, organizaçōes públicas e privadas, instituiçōes e governança; (ii) discutir as condiçōes sob as quais o aprendizado, a acumulação das capacidades produtivas e inovadoras e o uso efetivo dessas capacidades ocorrem; (iii) determinar em que sentido o tipo de governança, modelo de competição e estrutura de mercado local, nacional e internacional influenciam a evolução do arranjo; (iv) investigar em que grau a competitividade dos arranjos é sustentável e dinâmica, considerando a imersão social, a articulação com o sistema local de inovação e os principais elementos competitivos, tais como qualidade do produto, valor adicionado e produtividade do trabalho; (v) examinar a influência do regime 
macroeconômico e das politicas nacionais e locais, implicitas e explicitas na evolução do arranjo".

Em paralelo ao desenvolvimento dessas formulações, observa-se o aumento do interesse por pesquisas que procuram discutir os impactos da consolidação de relacionamentos sistemáticos entre agentes a partir de uma perspectiva analítica que privilegia como unidade de análise as "redes de firmas". O enfoque de redes de firmas tem recebido crescente atenção na literatura econômica especializada, podendo ser aplicado tanto à análise da estrutura interorganizacional dos arranjos, como à investigação do modus operandi $i^{3}$ destes, representando, portanto, um importante instrumento analítico e metodológico para a compreensão de sistemas produtivos em diferentes estágios de evolução tecnológica (Silva, 2004:71). Britto argumenta que esse recorte remete a "uma metáfora representativa das interdependências produtivas e tecnológicas que caracterizam ambientes econômicos complexos”, envolvendo "arranjos institucionais que possibilitam uma organização eficiente de atividades econômicas através da coordenação de ligações sistemáticas estabelecidas entre firmas inseridas em cadeias produtivas" (Britto, 1999:1; Albagli \& Britto, 2003:22).

No que tange à formação de "redes de firmas", Albagli e Britto destacam que estas surgem "por meio da consolidação de vínculos sistemáticos entre firmas, os quais assumem diversas formas: aquisição de partes de capital, alianças estratégicas, externalização das funções da empresa” (2003:22). Essas redes podem também estar configuradas em diferentes dimensões, podendo envolver "diferentes elos de uma determinada cadeia produtiva (conformando redes cliente-fornecedor ou produtorusuário), bem como estarem vinculadas a diferentes dimensões espaciais a partir das quais conformam-se redes locais, regionais, nacionais e supranacionais" (Britto, 1999; Albagli \& Britto, 2003).

Segundo Britto (1999:25), dependendo da morfologia que define uma determinada rede de firmas é possível correlacionar sua estrutura aos diversos "fluxos" internos que circulam através das suas diversas ligaçōes internas. Nesse sentido, dois tipos fundamentais de fluxos são identificados:

3 Esse tipo de análise privilegia a discussão do formato institucional subjacente para explicar a organização produtiva em forma de redes. Nesse sentido, "no caso das redes de firmas, é possível identificar algumas particularidades das posições relativas ocupadas pelos agentes no interior do arranjo. Estas posições estão associadas a uma determinada 'divisão do trabalho' que conecta os diferentes agentes visando atingir determinados objetivos. A consolidação desta divisão de trabalho é uma conseqüência natural da diversidade de atividades necessárias à produção de determinado bem, envolvendo a integração de capacidades operacionais e competências organizacionais dos agentes, bem como a compatibilização de tecnologias incorporadas nos diferentes estágios das cadeias produtivas" (Britto, 1999:18). 
1) fluxos tangíveis baseados em transações sistemáticas (em geral balizadas por relações contratuais), que envolvem a transferência de insumos e produtos e são passíveis de serem mensurados; e

2) fluxos intangíveis, que correspondem à circulação de informações (de caráter tácito ou codificado) no âmbito da rede, envolvendo ativos intangíveis dotados de valor estratégico para os agentes que o retêm, os quais são de mais difícil mensuração.

Nessa perspectiva, as redes de firmas são concebidas como instâncias que permitem a aglutinação e criação de competências ao longo do tempo, por meio de processos interativos de aprendizado institucionalmente condicionados. Basicamente, essas redes operam como estruturas de coordenação que permitem integrar competências individuais complementares, convertendo-as em fator indutor da exploração de novas oportunidades. No que concerne ao processo de coordenação intrarredes, Britto (1999) destaca três dimensões internas:

1) um processo de cooperação técnico-produtiva - associado à divisão do trabalho e à coordenação de funções produtivas entre os diversos agentes inseridos na rede, que estruturam sistemas técnico-produtivos com características específicas;

2) um processo de coordenação coletiva interno à rede - que remete a estrutura de poder subjacente a esses arranjos e ao balanceamento dos princípios de concorrência e cooperação mas articulações entre os agentes que a integram; e

3) um processo de cooperação tecnológica que se estabelece entre os agentes, relacionado à integração de competências e à coordenação dos esforços inovativos.

$\mathrm{Na}$ sistematização das evidências empíricas relacionadas à formação de redes de firmas, Britto (1999) propõe diferentes "modelos estilizados"4 representativos dessas redes. No âmbito mais específico de redes associadas a relações de subcontratação comandadas por uma firma principal - como no caso da Petrobras no aglomerado de Macaé -, é comum observar-se uma segmentação interna dessas redes, distinguindo-se um núcleo (ou segmento primário) baseado em relações interindustriais de caráter mais cooperativo, de uma "periferia" (ou segmento secundário) da rede, na qual prevalecem relações menos cooperativas, que se aproximam daquelas puramente mercantis.

4 Para uma análise mais detalhada do modus operandi de cada um dos modelos propostos, ver Britto (1999), cap. IV. 
No núcleo (ou segmento primário) dessas redes, o agente contratado desempenha uma função de concepção e desenvolvimento, adequando-se à especificação de resultados e às normas funcionais definidas pelo contratante, mas gozando de autonomia para desenvolver o produto de acordo com suas competências. A informação técnica que circula no arranjo é extremamente densa e sofisticada nesse segmento, movendo-se em um duplo sentido (two-way), de modo a compatibilizar patamares de eficiência técnico-produtiva e a integração das competências tecnológicas e organizacionais dos agentes envolvidos no arranjo. Estabelece-se, desse modo, uma interdependência bilateral, que, ao se aprofundar ao longo do tempo, dificulta a substituição dos agentes envolvidos, criando "barreiras à saída", que são específicas ao arranjo. Além disso, a necessidade de conservar um intercâmbio permanente de informações favorece a redução do número de agentes com os quais serão estabelecidas relaçôes de "primeiro nível". Nesse segmento, a flexibilidade produtiva associa-se a práticas cooperativas que permitem adaptações coordenadas em face da evolução do mercado, tornando-as menos traumáticas para os agentes envolvidos. Em consequência, a resposta dos produtores a problemas com fornecedores está geralmente baseada em mecanismos de negociação, orientados por uma lógica cooperativa de longo prazo. A forte interatividade das relaçôes no segmento primário torna o objeto da coordenação "multidimensional", envolvendo, dentre outros aspectos, a garantia da qualidade do insumo ou equipamento fornecido, a compatibilização do fluxo de abastecimento às necessidades do contratante e a incorporação contínua de inovaçôes tecnológicas.

Em contraste, no segmento secundário (ou periférico) da rede predominam relaçooes entre agentes que se aproximam das relaçôes mercantis realizadas num mercado concorrencial, contemplando um baixo grau de interatividade e um fluxo informacional relativamente restrito. O funcionamento desse tipo de segmento - a partir de contratos pontuais periodicamente renovados - torna possível à firma contratante substituir com facilidade as firmas contratadas, minimizando os custos de turnover e favorecendo a flexibilidade operativa. As firmas subcontratadas realizam um conjunto de tarefas restritas, geralmente associadas à obtenção de uma peça ou componente que atenda aos requerimentos técnicos impostos pelo contratante. Nesse segmento, a "flexibilidade" associada à operação da rede envolve o ajustamento do ritmo das transaçôes comandadas pela firma principal em função das necessidades do mercado. Nessas condições o encargo mais pesado de um ajustamento em face da retração do mercado recai sobre os fornecedores, que terão o seu fluxo de encomendas repentinamente reduzido. 
Dentre os "modelos estilizados" de redes de firmas propostos por Britto (1999), cumpre também mencionar o modelo de "rede de produtos complexos", cujo modus operandi também apresenta características semelhantes às do sistema técnico-produtivo que define o segmento de exploração e produção off-shore de petróleo e gás (E\&P), objeto de análise deste artigo. O termo "complexo" é usado para refletir o número de componentes sob medida envolvidos, a amplitude de conhecimentos e habilidades requeridas e o grau de novos conhecimentos necessários tanto na produção como em outras dimensóes críticas dos produtos. Essas redes se caracterizam pela presença de "relacionamentos produtivos associados à geração de 'produtos complexos' de caráter único e customizado, que requerem a integração de diferentes sistemas de componentes" (Britto, 1999:146). Os bens e/ou serviços gerados são extremamente sofisticados, possuindo elevado valor unitário e sendo intensivos em engenharia e tecnologia, produzidos como itens unitários ou em partidas de produção customizadas, em função da necessidade de consumidores individuais. Esse modelo de rede, dada a complexidade técnica subjacente, se baseia na compatibilização de diferentes subsistemas, requerendo a integração de conhecimentos e competências extremamente diferenciados. Cada um desses subsistemas envolve um conjunto específico de tecnologias que necessitam ser integradas. Tais características específicas interferem diretamente na configuração do processo de inovação no âmbito dessas redes, em função da maior interação necessária entre os agentes. Em especial, o quadro analítico definido pelo sistema complexo apresenta características não-triviais no processo inovativo, das quais Dantas (1999:30) destaca:

1) crescente complexidade ao longo do tempo, que implica, na crescente necessidade de capacitação, performance e confiabilidade;

2) boa parte dos conhecimentos e habilidades necessários para o desenvolvimento e capacitação tecnológica é de natureza tácita, cuja codificação é problemática, o que fortalece os vínculos e interdependência dos agentes participantes;

3) alto grau de envolvimento produtor-usuário no processo de inovação, e o usuário é responsável por uma série de avanços incrementais a partir do projeto inicial, o que cria uma relação de longo prazo entre os agentes.

Dentre os exemplos de produtos complexos, destacam-se: automação bancária e industrial, motores e aeronaves, plantas e equipamentos para geração de energia nuclear; plataformas off-shore para exploração de petróleo; sistemas e robôs industriais, 
sistemas de satélite (Britto, 1999:248). No caso da bacia de Campos, a estruturação de um arranjo voltado para a produção de petróleo e do gás extraídos da plataforma continental requer a integração de diversos subsistemas em cada uma das etapas do processo de produção off-shore. Desse modo, no arranjo em questão, os fornecedores da Petrobras desenham e configuram seus produtos ou serviços de modo a atender os requerimentos de seu principal cliente, a Petrobras.

Em decorrência desse quadro, verifica-se que o modelo organizacional de exploração off-shore passa a agregar um conjunto bastante heterogêneo de atores que apresenta formas variadas de articulação entre si. No âmbito da cadeia produtiva, é possível destacar dois grupos distintos de atores. De um lado estão as operadoras que assumem grande parte da coordenação das atividades de prospecção, exploração, transporte e distribuição. De outro, encontram-se os fornecedores que oferecem uma ampla gama de materiais, equipamentos e serviços, com maior ou menor grau de especialização. A crescente necessidade de externalização de determinadas atividades para fornecedores especializados por parte das operadoras decorre da grande heterogeneidade associada às bases de conhecimentos e competências envolvidas nas atividades de exploração e produção de petróleo e gás natural (Furtado, 2003). Da mesma forma, verifica-se que a inter-relação entre operadoras e seu núcleo de fornecedores especializados apresenta um elevado grau de complexidade, na medida em que decisões das operadoras sobre as condições de suprimento implicam estudos detalhados de engenharia e simulações complexas da operação dos sistemas envolvidos (Bell \& Oldham, 1988:42).

No setor petrolífero, e em especial na atividade off-shore, a capacidade inovativa da atividade esbarra na necessidade de desenvolvimento de um amplo espectro de tecnologias de produção para atender novas especificações tanto dos produtos quanto do próprio processo de produção que envolvia essa nova atividade. Por se caracterizar como um "sistema de produção complexo", o progresso técnico na atividade petrolífera exige um esforço adicional por parte da companhia de petróleo em capacitar técnica e conomicamente seus fornecedores, de modo que estes possam atender todas as novas exigências. Ou seja, a participação das empresas fornecedoras no processo inovativo é fundamental, na medida em que toda e qualquer modificação técnica exige uma reformulação de projetos, produtos e processos por parte delas, para que estejam capacitadas a atenderem as novas especificações pertinentes da mudança técnica.

Segundo Dantas (1999), o entendimento da (inter)conectividade das várias pontas do processo inovativo na indústria do petróleo é crucial, visto que, apesar 
do papel de liderança que a companhia de petróleo exerce, o processo de capacitação deve ser analisado de maneira global, envolvendo toda indústria, incluindo-se então os elos fundamentais da cadeia, representados pelos fornecedores de insumos críticos e pelos institutos técnico-científicos. A importância da atividade de coordenação por parte da companhia de petróleo está intrinsecamente ligada à capacidade inovativa da própria empresa. A gerência de um sistema complexo diz respeito à arquitetura organizacional, visto que tais sistemas são marcados pela existência de várias alternativas que podem impor alterações relevantes na trajetória tecnológica, particularmente em ambientes marcados por rápida mudança tecnológica.

É importante destacar o caráter centralizador das companhias de petróleo nesse tipo de arranjo. Desse modo cabe a ela o direcionamento e planejamento das atividades inovativas e, além disso, a preocupação com a capacitação tecnológica dos diversos agentes envolvidos. A interação dessas empresas com fornecedores e com a infraestrutura científica e tecnológica torna-se fundamental, envolvendo a troca de informaçôes visando solucionar problemas inerentes às modificações de projetos ou viabilizar novos produtos demandados pela companhia de petróleo. Outro ponto importante é a formação, por parte da infraestrutura científica e tecnológica, de trabalhadores capacitados, como engenheiros e técnicos, para esse mercado de trabalho.

\section{0 Aglomerado Petrolífero de Macaé - Caracterização geral}

\subsection{Configuração estrutural do aglomerado}

A história do aglomerado petrolífero de Macaé começa com as primeiras atividades de exploração na bacia de Campos, iniciadas pela Petrobras em 1968, que resultariam na consolidação de uma densa infraestrutura produtiva e em uma ampla rede de empresas articuladas às atividades de $\mathrm{E} \& \mathrm{P}$, principalmente a partir da década de 1990. A instalação da Petrobras no município e a expansão da atividade petrolífera em seus domínios devem-se a dois fatores locacionais básicos:

1) à vantagem natural conferida a Macaé em função do Porto de Imbetiba, que representou, desde o início das atividades petrolíferas, um grande facilitador na logística da empresa; e

2) à proximidade de Macaé da bacia de Campos e, principalmente, do Rio de Janeiro. 
Esses fatores locacionais contribuíram para que Macaé fosse escolhida como a base de operações da Petrobras Unidade Bacia de Campos (Petrobras UN-BC) em detrimento de outro forte concorrente, o município vizinho de Campos dos Goytacazes.

Instaladas em Macaé encontram-se empresas de diversos ramos ligados direta e indiretamente às atividades de E\&P. Merecem destaque as grandes operadoras como a Petrobras, Shell, Total Fina Elf, Exxon Mobil, dentre outras, que demandam bens e serviços em diversas fases do processo de E\&P na BC. Devem-se mencionar ainda as empresas comerciais, prestadoras de serviços e industriais. No caso das empresas comerciais, destacam-se aquelas especializadas na venda de equipamentos elétricos, eletrônicos, metalúrgicos, de construção civil, de segurança do trabalho, de máquinas e equipamentos de pequeno e médio porte, de ferramentas etc. As empresas prestadoras de serviços dividem-se em dois subgrupos: as grandes prestadoras de serviços, caracterizadas, em geral, pelo elevado aporte tecnológico e de capital, responsáveis pelos grandes contratos com as operadoras atuantes na $\mathrm{BC}$, com destaque para a Petrobras; e as pequenas e médias empresas indústrias e de prestação de serviços, caracterizadas pelos baixos níveis tecnológicos e de aporte de capital.

Com relação às empresas de grande porte - com destaque para a Petrobras ${ }^{5}$ e empresas multinacionais -, estas estão diretamente envolvidas com projetos complexos envolvendo as principais fases da atividade petrolífera na $\mathrm{BC}$, a saber: exploração, desenvolvimento e produção de petróleo e gás. $\mathrm{Na}$ área de exploração, tais empresas atuam desenvolvendo serviços como: trabalhos de sísmica 3D, perfuração de poços, transporte e aluguel de plataformas. $\mathrm{Na}$ fase de desenvolvimento da produção, destacam-se empresas que prestam serviços relacionados à colocação de árvores de natal, instalação de dutos de óleo e gás, minifolds, bombas elétricas, instalação de plataformas fixas e flutuantes, reparos navais etc. Com relação à produção propriamente, destacam-se empresas que atuam na área de projetos de produção, serviços de engenharia elétrica, de sistemas de informação, mecânica, reparos navais, acondicionamento e transporte de óleo e gás. Em todas as três áreas, destacam-se as empresas especializadas na prestação de serviços de consultoria, inclusive na elaboração de projetos, nas áreas de engenharia, meio ambiente e financeira (project finance). Já as empresas de pequeno e médio porte atuam, normalmente, em sistemas de subcontração ${ }^{6}$ nas áreas de construção civil, caldeiraria, soldagem,

5 A Petrobras enquanto empresa dominante (âncora) é responsável pela maior parcela da demanda de bens e serviços na $B C$.

6 Elementos que tipificam o sistema de governança que envolve os mecanismos de coordenação inerentes ao APM são apresentados na análise microeconômica, cap. V. 
pequenos reparos, usinagem, pintura, hotelaria, catering etc. Essas empresas, em geral, atuam em segmentos que atendem a indústria petrolífera, nos quais a complexidade das operações, o nível tecnológico e o montante dos investimentos para o desenvolvimento do negócio são relativamente baixos.

De modo a subsidiar a análise, procurou-se utilizar uma metodologia para a caracterização do APM, baseada numa desagregação a quatro dígitos na classificação CNAE do IBGE. Nesse sentido, utilizou-se como fonte básica de informações os dados da Relação Anual de Informações Sociais (RAIS), produzidos pela Secretaria de Políticas de Emprego e Salário do Ministério do Trabalho e Emprego (MTb). As fontes básicas de informações utilizadas referem-se aos dados da RAIS para os anos de 2000 e 2005, relativas aos trabalhadores formais registrados, ao número de estabelecimentos presentes nos diversos ramos de atividades e ao valor total das remuneraçôes geradas. Assim, procurou-se selecionar classes CNAE relacionadas à estruturação daquele arranjo, as quais foram divididas em quatro grupos:

1) atividades-núcleo do aglomerado;

2) fabricação de insumos e componentes;

3) serviços de construção; e

4) atividades de apoio à logística e transporte. ${ }^{7}$

Considerando a metodologia descrita, foi identificado no aglomerado investigado um total de 317 estabelecimentos ligados diretamente à indústria petrolífera, responsáveis pela geração de 28.664 empregos formais no ano de 2005

7 Esses grupos de atividades foram definidos a partir da agregação das atividades (classes CNAE): 1) Atividades-núcleo do aglomerado: 11.100 - extração de petróleo e gás natural; 11.207 - atividades de serviços relacionados com a extração de petróleo e gás; 2) Fabricação de insumos e componentes: 28.118 - fabricação de estruturas metálicas para edifícios, pontes, torres; 28.398 - têmpera, cimentação e tratamento térmico do aço, serviços de usinagem; 29.130 fabricação de válvulas, torneiras e registros; 29.297 - fabricação de outras máquinas e equipamentos de uso geral; 29.513 - fabricação de máquinas e equipamentos para prospecção e extração de petróleo; 29.955 - manutenção e reparação de máquinas e equipamentos de uso na extração mineral e construção; 29.963 - manutenção e reparação de máquinas e equipamentos de uso específico; 33.308 - fabricação de máquinas, aparelhos e equipamentos de sistemas eletrônicos; 35.114 - construção e reparação de embarcações e estruturas flutuantes; 3) Serviços de construção: 45.250 - obras de montagem; 45.292 - obras de outros tipos; 45.497 - outras obras de instalações; 4) Atividades de logística de transporte: 55.131 - estabelecimentos hoteleiros; 55.190 - outros tipos de alojamento; 60.267 - transporte rodoviário de cargas em geral; 60.305 - transporte dutoviário; 61.115 - transporte marítimo de cabotagem; 61.220 - transporte de carga por navegação; 62.200 - transporte aéreo não-regular; 63.126 - armazenamento e depósitos de cargas; 63.215 - atividades auxiliares dos transportes terrestres; 63.223 - atividades auxiliares dos transportes aquaviários; 63.231 - atividades auxiliares dos transportes aéreos; 63.304 - atividades de agências de viagens e organizadores de viagens; 63.401 - atividades relacionadas à organização do transporte de cargas; 71.323 - aluguel de máquinas e equipamentos para construção e engenharia. 
(considerando informações da RAIS), conforme aponta a Tabela 2. A presença da Petrobras e de grandes empresas que a ela prestam serviços, por meio de unidades localizadas em Macaé, reflete-se no expressivo tamanho médio geral dos estabelecimentos no aglomerado (90 empregados por estabelecimento) e no elevado nível de remuneração média mensal por empregado (aproximadamente $\mathrm{R} \$ 4.314,00 \mathrm{em}$ 2005). Verifica-se ainda que a participação do aglomerado no total do emprego e das remunerações do município de Macaé era particularmente elevada, atingindo $38 \%$ no primeiro caso e $70 \%$ no segundo.

Quando se observa a taxa de crescimento acumulado composto ${ }^{8}$ nos empregos formais para as atividades selecionadas no período 2000-2005, observa-se um crescimento anual de $21,7 \%$, o que evidencia o dinamismo do aglomerado. Esse crescimento foi mais expressivo nas "atividades-núcleo do aglomerado" e na "fabricação de insumos e componentes". O crescimento anual das remunerações nessas atividades também foi particularmente expressivo, atingindo mais de $50 \%$ ao ano ao longo do período considerado. Em termos da evolução do tamanho médio de estabelecimento, observa-se um crescimento mais acelerado nas "atividades-núcleo do aglomerado" ("extração de petróleo e gás natural" e "atividades de serviços relacionados com a extração de petróleo e gás"), com um crescimento médio anual de $21,1 \%$ ao longo do período. Em termos de remuneração média, observa-se um crescimento médio de $25,5 \%$ ao longo do período considerado para o conjunto de atividades integradas ao aglomerado. Comparativamente ao conjunto das atividades econômicas, as taxas de crescimento anual das atividades do aglomerado foram mais expressivas, tanto no caso de empregos como para estabelecimentos e remunerações. Como consequência, a participação do aglomerado no total de empregos da microrregião de Macaé se elevou de $25 \%$ para $38 \%$, enquanto a participação do mesmo no total de remunerações se elevou de $42 \%$ para $70 \%$. Esta evolução ressalta o papel absolutamente fundamental que o aglomerado desempenha para o desenvolvimento econômico da região.

As empresas off-shore que atuam em Macaé encontram-se na fase final da cadeia produtiva da indústria petrolífera, isto é, desenvolvem basicamente serviços intensivos em engenharia e atividades técnicas, envolvendo a integração de sistemas e componentes complexos, manutenção de equipamentos, sistemas operacionais e serviços associados ao desenvolvimento das atividades off-shore. A representação esquemática do APM, apresentada na Figura 1, fornece uma visão geral dos grupos de empresas, assim como das instituiçôes que o constituem.

8 A taxa de crescimento acumulado composto é dada pela fórmula $\left\{\left[(\text { valor final/valor inicial })^{1 / n}\right]-1\right\}$, onde $n$ corresponde ao número de anos $(n=5)$. 
TABELA 2

Características das atividades do Aglomerado Petrolífero de Macaé - 2000 e 2005

\begin{tabular}{|c|c|c|c|c|c|c|c|}
\hline $\begin{array}{l}\text { Atividades } \\
\text { integradas } \\
\text { ao aglomerado }\end{array}$ & $\begin{array}{l}\text { Atividades- } \\
\text { núcleo } \\
\text { do } \\
\text { aglomerado }\end{array}$ & $\begin{array}{l}\text { Fabricação } \\
\text { de insumos } \\
\text { e compo- } \\
\text { nentes }\end{array}$ & $\begin{array}{l}\text { Serviços } \\
\text { de cons- } \\
\text { trução }\end{array}$ & $\begin{array}{l}\text { Atividades } \\
\text { de logís- } \\
\text { tica de } \\
\text { transporte }\end{array}$ & $\begin{array}{l}\text { Subtotal } \\
\text { Petróleo e } \\
\text { atividades } \\
\text { associadas }\end{array}$ & $\begin{array}{l}\text { Total da } \\
\text { microrregião } \\
\text { (Macaé) }\end{array}$ & $\begin{array}{l}\text { Comparaçãc } \\
\text { (aglomerado } \\
\text { total) }\end{array}$ \\
\hline \multicolumn{8}{|c|}{ Número de empregados formais } \\
\hline Empregos (2000) & 4.395 & 1.437 & 2.896 & 1.997 & 10.725 & 42.836 & $25 \%$ \\
\hline Empregos (2005) & 14.919 & 4.100 & 4.230 & 5.415 & 28.664 & 75.376 & $38 \%$ \\
\hline $\begin{array}{l}\text { Taxa de var. anual } \\
\text { composta (2000-2005) } \\
\text { Empregos }\end{array}$ & $27,7 \%$ & $23,3 \%$ & $7,9 \%$ & $22,1 \%$ & $21,7 \%$ & $12 \%$ & $1,82 \%$ \\
\hline \multicolumn{8}{|c|}{ Número de estabelecimentos ativos } \\
\hline Estabelecimentos (2000) & 36 & 18 & 28 & 69 & 151 & 2.920 & $5,2 \%$ \\
\hline Estabelecimentos (2005) & 47 & 44 & 66 & 160 & 317 & 4.076 & $7,8 \%$ \\
\hline $\begin{array}{l}\text { Taxa de var. anual } \\
\text { composta (2000-2005) } \\
\text { Estabelecimentos }\end{array}$ & $5,5 \%$ & $19,6 \%$ & $18,7 \%$ & $18,3 \%$ & $16 \%$ & $6,9 \%$ & $2,32 \%$ \\
\hline \multicolumn{8}{|c|}{ Valor total de remunerações ( $R \$$ ) - Média mensal no ano } \\
\hline Remunerações (2000) & 9.157 .498 & 1.108 .575 & 2.221 .756 & 2.390 .741 & 14.878 .570 & 35.656 .246 & $41,7 \%$ \\
\hline Remunerações (2005) & 90.326 .566 & 9.564 .215 & 8.399 .037 & 15.371 .385 & 123.661 .203 & 177.690 .230 & $69,6 \%$ \\
\hline $\begin{array}{l}\text { Taxa de var. anual } \\
\text { composta (2000-2005) } \\
\text { Remunerações }\end{array}$ & $58,1 \%$ & $53,9 \%$ & $30,5 \%$ & $45,1 \%$ & $52,7 \%$ & $37,9 \%$ & $1,39 \%$ \\
\hline \multicolumn{8}{|c|}{ Tamanho médio - Número de trabalhadores por estabelecimento } \\
\hline Tamanho médio (2000) & 122,1 & 79,8 & 103,4 & 28,9 & 71,0 & 14,7 & 4,84 \\
\hline Tamanho médio (2005) & 317,4 & 93,2 & 64,1 & 33,8 & 90,4 & 18,5 & 4,89 \\
\hline $\begin{array}{l}\text { Taxa de var. anual } \\
\text { composta (2000-2005) } \\
\text { Tamanho médio }\end{array}$ & $21,1 \%$ & $3,1 \%$ & $-9,1 \%$ & $3,2 \%$ & $4,9 \%$ & $4,7 \%$ & $1,04 \%$ \\
\hline \multicolumn{8}{|c|}{ Remuneração mensal por trabalhador (R\$) - Média no ano } \\
\hline $\begin{array}{l}\text { Remuneração } \\
\text { média (2000) }\end{array}$ & 2.084 & 771 & 767 & 1.197 & 1.387 & 832 & 1.67 \\
\hline $\begin{array}{l}\text { Remuneração } \\
\text { média (2005) }\end{array}$ & 6.054 & 2.333 & 1.986 & 2.839 & 4.314 & 2.357 & 1.83 \\
\hline $\begin{array}{l}\text { Taxa de var. anual } \\
\text { composta (2000-2005) } \\
\text { Remuneração média }\end{array}$ & $23,8 \%$ & $24,8 \%$ & $21 \%$ & $18,9 \%$ & $25,5 \%$ & $23,1 \%$ & $1,10 \%$ \\
\hline
\end{tabular}

Fonte: elaboração própria a partir de dados da RAIS (2000 e 2005). 
Essas empresas estão instaladas principalmente na região urbana de Macaé e podem ser divididas em dois grandes grupos:

1) empresas diretamente ligadas às atividades off-shore, tais como prestadoras de serviços e provedores de insumos, representados na parte superior da Figura 1; e

2) empresas que atuam em atividades de suporte, tais como transporte, construção civil, alojamento e alimentação e outras atividades, representados em sua parte inferior esquerda. No lado direito da Figura 1, representa-se o grupo de instituições de apoio que dão suporte ao aglomerado, além do conjunto de instituições sediadas em Macaé e no Rio de Janeiro, responsáveis pelas atividades de ciência e tecnologia voltadas para as atividades de P\&D e inovação tecnológica.

No centro do aglomerado está a Petrobras que, juntamente com outras 11 operadoras, ${ }^{9}$ define a dinâmica produtiva do aglomerado. A assimetria que se verifica no APM deve-se, sobretudo, à concentração de poder pela Petrobras em decorrência do monopólio das atividades de E\&P exercido pela estatal até a implementação da Lei do Petróleo em 1997. Nas décadas que antecederam o fim do monopólio, a Petrobras descobriu e passou a explorar as jazidas mais promissoras da BC e montou uma ampla infraestrutura operacional e produtiva. Em 2003, a Petrobras contava com 41 plataformas de produção fixas e flutuantes, 4.400 quilômetros de redes de oleodutos e de gasodutos, 38 campos de produção, 673 poços perfurados, 732 poços exploratórios e um total de 1.405 poços exploráveis (Petrobras, 2006). Considerando a expressiva produção de petróleo e gás da $\mathrm{BC}$, os investimentos realizados pela Petrobras em atividades de E\&P dão uma noção do peso da estatal no APM. Apenas no primeiro semestre de 2006, a Petrobras investiu US\$ 6,8 bilhões em atividades de E\&P no Brasil. Desse total, quase a metade (US\$ 3,2 bilhões), ou seja, 47\%, foi despendida diretamente no estado do Rio de Janeiro, na compra de bens e serviços para a BC (Azevedo, 2006). ${ }^{10}$

Quanto às articulações interindustriais, destacam-se as atividades desempenhadas por empresas de prestação de serviços, contratadas diretamente pela Petrobras e pelas outras operadoras atuantes na $\mathrm{BC}$, articuladas às atividades-fins, a saber: exploração, desenvolvimento e produção de petróleo e gás. As atividades de "exploração" de

9 Total Fina Elf, Royal Dut Shell, Exxon Móbil, Pan Canadian, Wintershull, Devon, Chevron, Texaco, Agip, Unocal, Ocean Energy INC. Destaca-se que a maioria dessas operadoras desenvolvem a exploração de blocos em parceria com a Petrobras.

10 Informações do presidente da Petrobras, José Sérgio Gabrielli de Azevedo, em palestra proferida na Associação Comercial do Rio de Janeiro, em 31 de outubro de 2006. 
FIGURA 1

Mapa do Aglomerado Petrolífero de Macaé

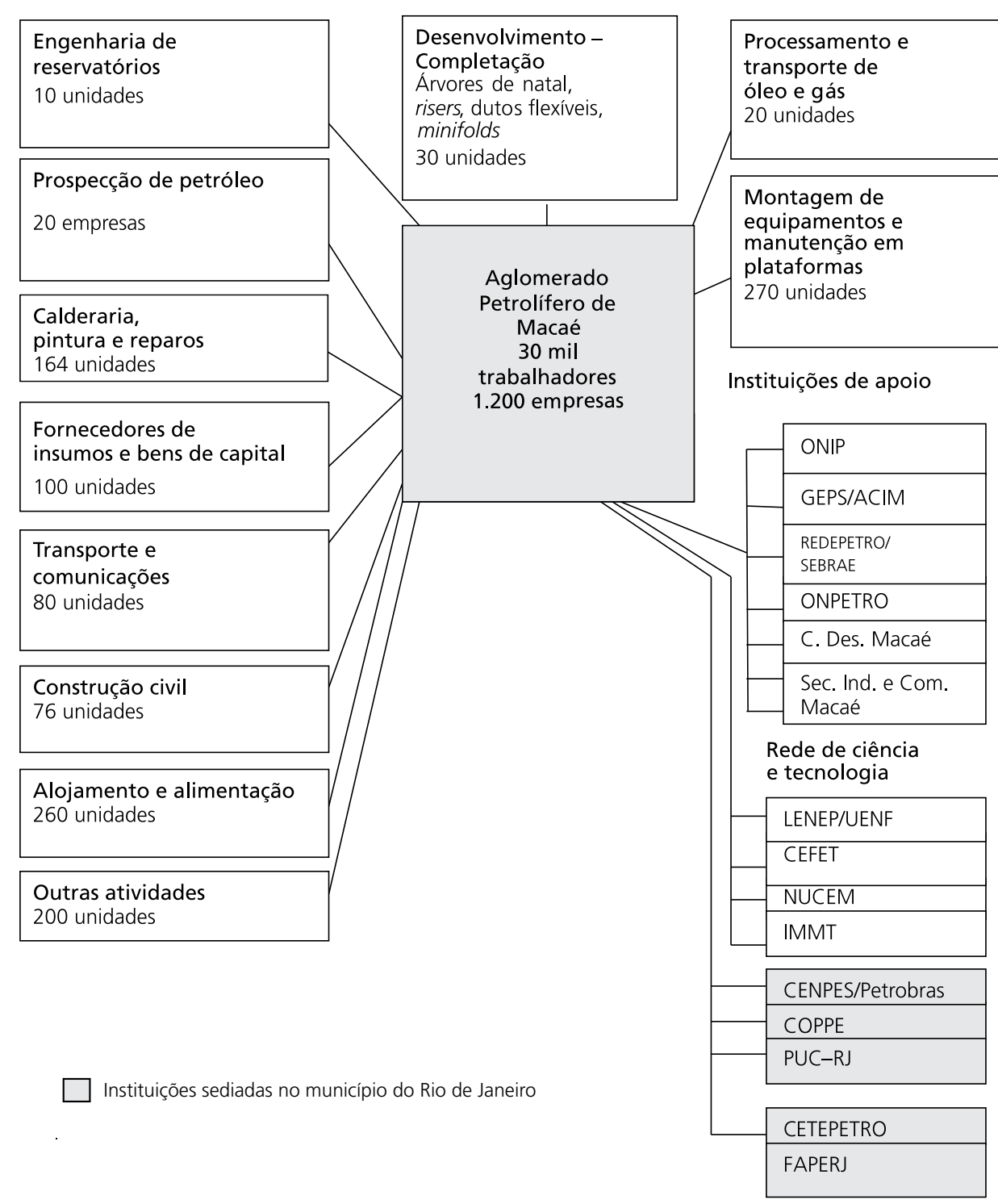

Fonte: elaboração própria baseada em Nadiv (1995). 
petróleo e gás englobam diversos serviços, visando principalmente à descoberta de novos reservatórios. Participam desse segmento, empresas responsáveis por levantamentos geológicos e perfuração de poços. As atividades relacionadas ao "desenvolvimento" da estrutura de produção de petróleo e gás englobam serviços relacionados à cimentação dos poços de petróleo (completação), à instalação de bombas para extrair o petróleo dos reservatórios (árvores de natal) e à engenharia de construção de dutos para transporte do óleo e do gás. Já as atividades de "produção" englobam a extração propriamente de petróleo e de gás, seu processamento (separação do óleo da água e do gás) e transporte para os navios-tanque ou refinarias. Integrados às atividades de E\&P estão os serviços de montagem de equipamentos, manutenção de plataformas, caldeiraria, pintura e reformas. Outras articulaçôes interindustriais relevantes agregam as empresas fornecedoras de insumos e bens de capital, de transporte e comunicações, alojamento e alimentação, e outras atividades.

Tanto a Petrobras como as demais operadoras e prestadoras de serviços atuam na bacia de Campos ao longo das etapas finais da cadeia produtiva off-shore. Isso significa que uma parte significativa das etapas da cadeia produtiva que determinam os encadeamentos interindustriais da indústria off-shore se desenvolve fora do Aglomerado Petrolífero de Macaé, compreendendo a produção de bens, insumos e serviços em outras regióes do país, como, por exemplo, Rio de Janeiro, São Paulo e Minas Gerais. Além disso, esses encadeamentos vão além das fronteiras brasileiras quando se trata da importação de bens de capital, serviços e equipamentos complexos, tais como plataformas, navios-tanque, peças e equipamentos diversos.

Em termos da localização espacial, observa-se que as empresas que constituem o Aglomerado Petrolífero de Macaé se concentram em três bairros ou áreas industriais: Imboassica, Novos Cavalheiros e Parque dos Tubos. A maior empresa do aglomerado é a Petrobras, ${ }^{11}$ cuja sede está localizada no Bairro de Imbetiba, próximo ao porto que recebeu o mesmo nome. A localização da Petrobras é privilegiada pela existência de infraestruturas físicas, como o Porto de Imbetiba e o Aeroporto de Macaé. No que tange às pequenas empresas, destaca-se que estas se concentram basicamente nas áreas periféricas da cidade, onde é possível observar a ausência de toda sorte de infraestrutura, inclusive saneamento básico. Essas concentraçôes industriais ocorrem na periferia do Bairro de Imbetiba, bem como na entrada da cidade de Macaé e na proximidade

11 As infraestruturas de produção onshore - definidas especialmente pela maior e mais antiga operadora da BC, a Petrobras, ao longo das últimas décadas em Macaé - vão influenciar decididamente na localização das aglomerações de empresas de suporte à atividade petrolífera no município, que passam a se situar em torno das principais áreas industriais ocupadas pela estatal, a saber: Parque dos Tubos, em Imbetiba (sede da Petrobras) e no Complexo de Armazenamento e Processamento e Transporte de Gás Natural da Petrobras - Cabiúnas. 
do centro da cidade - no entorno do Aeroporto de Macaé. As empresas de grande e médio porte, por sua vez, concentram-se essencialmente no bairro de classe média alta, Novos Cavalheiros, bem como na região do chamado Parque dos Tubos - nas margens da Rodovia Amaral Peixoto. A Rua Professor Aristeu da Silva, por exemplo, localizada no Bairro Novos Cavalheiros, concentra mais de 350 empresas de médio e grande porte, sobretudo multinacionais, especializadas na prestação de serviços em E\&P off-shore. No Bairro Novos Cavalheiros, encontram-se as filiais de algumas das maiores empresas off-shore do mundo, como Halliburton, Schlumberger, Transocean, Precision Internacional, DVN, dentre outras. No Bairro Parque dos Tubos, localiza-se a divisão de tubulações da Petrobras e o depósito de equipamentos e materiais da empresa. Observa-se ainda a presença de empresas de atuação internacional, como a Lousianna Drilling, Petroserv, Weatherford, Cooper Cameron.

\subsection{Aglomerado Petrolífero de Macaé - Arquitetura da rede de firmas}

A partir da vigência da Lei do Petróleo, de agosto de 1997, o número de empresas off-shore sediadas em Macaé passou a crescer de forma substancial, dando novos contornos à organização industrial até então vigente no município. Empresas nacionais e estrangeiras, industriais e prestadoras de serviços, de pequeno, médio e grande porte passaram a atuar em Macaé. Segundo a Secretaria de Fazenda de Macaé (2003:2), no período 1984-2004, quando a produção petrolífera se intensificou, 4.126 empresas instalaram-se no município fluminense, sendo 2.016 industriais e comerciais e 2.110 prestadoras de serviços.

A "arquitetura organizacional" da rede de firmas que se estruturou em Macaé pode ser mais bem-detalhada a partir de uma análise sobre a heterogeneidade das relaçôes existentes nesse arranjo, a partir dos condicionantes técnico-produtivos inerentes à produção off-shore de petróleo e gás natural. Inicialmente, cumpre destacar que o processo produtivo associado à produção de óleo e gás em águas profundas e ultraprofundas engloba três etapas:

1) atividades de exploração - envolvem estudos sísmicos e geológicos, perfurações exploratórias de poços e avaliação de jazidas petrolíferas;

2) atividades de desenvolvimento - são atividades relacionadas à instalação dos equipamentos necessários ao processo de produção de petróleo e gás: instalação de plataformas, rises submarinos, bombas etc.; 
3) atividades de produção - relacionam-se ao conjunto de procedimentos técnicos e operacionais voltados para a produção de petróleo e gás, incluindo o processamento (separação do óleo do gás da água) e o transporte do óleo e do gás, seja por meio de dutos ou de navios-tanque.

Cada uma dessas atividades integra subsistemas geradores de subprodutos e serviços complexos que necessitam ser compatibilizados por meio de projetos sofisticados.

A intensificação das atividades petrolíferas na BC por parte da Petrobras e demais operadoras vem consolidando uma nova dinâmica industrial em Macaé, onde é possível identificar a presença de três grupos distintos de empresas atuantes no aglomerado, a saber:

1) as grandes operadoras, como, por exemplo, a Petrobras, YFP e Shell - diretamente responsáveis pelas atividades de exploração, desenvolvimento e produção de petróleo e gás;

2) as grandes empresas estrangeiras prestadoras de serviços, tais como a Halliburton, Schlumberger e Transocean; e, por fim,

3) o grupo das pequenas e médias empresas nacionais prestadoras de serviços, que atuam, em geral, no sistema de subcontratação.

O primeiro grupo, o das operadoras, é constituído por empresas transnacionais, de grande porte, que atuam em diversos segmentos da indústria petrolífera, tanto no upstream quanto no dowstream. ${ }^{12}$ No caso da bacia de Campos, o destaque é para a Petrobras, que possui mais de $80 \%$ dos ativos de produção off-shore. Das 11 operadoras que atuam em Macaé, pelo menos 9 desenvolvem projetos de E\&P em associação com a Petrobras, com exceção da Shell, que opera sozinha uma área promissora na BC. O segundo grupo de empresas que operam na BC é composto pelas transnacionais. Em geral, trata-se de grandes empresas de padrão internacional que atuam no desenvolvimento de produtos e serviços customizados de elevado grau de complexidade, envolvendo as atividades de exploração, desenvolvimento e produção. Empresas como a Hallibourton, Slumberger, Weatherfod e Pride estão inseridas nesse contexto e dividem com outras grandes empresas petrolíferas o

12 O segmento upstream da indústria relaciona-se às atividades de exploração, desenvolvimento e produção de petróleo e gás. Já o segmento dowstream relaciona-se às atividades de transporte, refino e comercialização tanto do petróleo e do gás, quanto de seus derivados. 
mercado da BC. Como já mencionado, o terceiro grupo de empresas sediadas em Macaé é o das prestadoras de serviços de pequeno e médio porte. A característica principal desse grupo de empresas é o baixo nível tecnológico e o pequeno aporte de capital disponível para investimentos em inovação tecnológica e qualificação da mão de obra. Essas empresas participam no mercado principalmente por mecanismos de subcontratação atuando com as grandes prestadoras de serviços, as quais são responsáveis com a Petrobras e demais operadoras pelo gerenciamento de grandes projetos de engenharia e de serviços da BC. ${ }^{13}$ Apesar dessa tendência geral, uma parcela das PMEs ainda mantém contratos diretamente com a Petrobras, visando o fornecimento de bens e serviços. Nesse sentido, destacam-se empresas que atuam nas áreas de mecânica, elétrica, soldagem, caldeiraria, catering, transporte de cargas, pintura, pequenos reparos e metalurgia.

Mais recentemente, a mudança no modelo de gestão dos projetos na indústria do petróleo abriu espaço para a atuação das empresas de engenharia e montagem como EPCistas. A saída da Petrobras da atuação como contratante direto resultou num alargamento do mercado para as empresas de engenharia, implicando um estímulo à busca de maior capacitação por parte dessas empresas. No entanto, o papel dessas empresas na coordenação dos fornecedores domésticos ainda é incipiente, muito distante do papel exercido anteriormente pela Petrobras, principalmente no caso do off-shore. Muitas dessas empresas ainda são infantes nas atividades petrolíferas, sendo dependentes da Petrobras, que é responsável pela confecção dos projetos básicos, evidenciando uma capacidade ainda limitada de estas estruturarem e administrarem uma rede complexa de fornecedores. Observa-se também que as grandes empresas internacionais parapetroleiras associadas a serviços na área do petróleo - que assumiram no plano internacional a função adicional de coordenação de redes de fornecedores e de desenvolvimento de tecnologias de perfuração e desenvolvimento de poços - também ainda têm uma atuação limitada no Brasil.

13 Nesse sentido, uma crescente importância tende a ser atribuída aos chamados EPCistas no processo de subcontratação. Nos contratos do tipo Engineering, Procurement and Construction (EPC), um contratante principal, geralmente uma empresa de engenharia a serviço da Petrobras, fica a cargo do desenvolvimento de projetos através da subcontratação de outras empresas fornecedoras de equipamentos e serviços. Além da execução do projeto, as chamadas EPCistas assumem o papel de integração das diferentes etapas do projeto, bem como as tarefas associadas à negociação de preços e controle da qualidade dos diferentes equipamentos que integram o projeto (Furtado et al., 2003). Nos contratos tipo EPC, as aquisições de materiais e de equipamentos e a contratação dos serviços são conduzidas por uma fornecedora de bens e serviços que centraliza as atividades - a qual opera como contratante principal. Esta última subcontrata atividades específicas de terceiros, possibilitando às companhias de petróleo se distanciaram da coordenação de suas redes de fornecedores. No Brasil, existem algumas empresas atuando como contratantes principais, dentre as quais destacam-se: Technint, Ultratec, Montreal, Camargo Correa, Odebrecht, Setal, Promon, Marítima. Há, também, crescente participação de grupos estrangeiros nas licitações de compras da Petrobras, tais como a ABB-Lumus Global, Bechtel, Foster Wheeler, Kellogg Brown \& Root (ANP, 1999). 
Nos diversos segmentos de fornecedores especializados, apesar de se observar taxas de inovação mais altas que a média da indústria brasileira, os investimentos inovativos, particularmente em $\mathrm{P} \& \mathrm{D}$, ainda são relativamente baixos, principalmente em comparação ao padrão internacional. Assim, no contexto nacional, o processo de reestruturação de articulações interindustriais nas atividades de exploração off-shore ainda está incompleto, dado o papel ainda incipiente dos EPCistas, os limites da atuação de parapetroleiras no país e capacitação ainda limitada de diversos segmentos de fornecedores especializados.

\subsection{Infraestrutura de ciência e tecnologia}

A produção off-shore demanda vultosos investimentos em infraestrutura produtiva e em tecnologia; ${ }^{14}$ assim, na medida em que a indústria avança para a exploração e produção de petróleo em águas mais profundas, como ocorre na BC, novos equipamentos, métodos e técnicas de se explorar e produzir petróleo e gás são requeridos. Isso sinalizam no sentido da necessidade de se construir uma sólida rede de ciência e tecnologia que ofereça suporte à indústria petrolífera na BC, de modo a possibilitar o incremento da inovação tecnológica local e regional, a maior qualificação da mão de obra e a diversificação produtiva das empresas nacionais provedoras de insumos e serviços que atuam no APM.

A infraestrutura de ciência e tecnologia de suporte à indústria petrolífera na BC vem-se desenvolvendo no Rio de Janeiro, desde o início dos anos 1970, e, mais recentemente, em Macaé. Para viabilizar projetos de alto teor de inovação que se localizam na fronteira do conhecimento - como no caso da exploração e produção de óleo e gás em águas profundas -, a Petrobras tem procurado se associar de forma cooperada com universidades e instituições de pesquisa, para obter o necessário suporte acadêmico no nível de pesquisa aplicada. A intensificação de relacionamentos entre a Petrobras e instituições de C\&T reflete também algumas mudanças institucionais na regulação do setor. As mudanças na legislação foram promovidas pela Agência Nacional do Petróleo, Gás Natural e Bioenergia (ANP), em 1998, a partir das quais as empresas do setor de petróleo e gás passaram a ter de aplicar $1 \%$ dos recursos de participação especial em projetos de $\mathrm{P} \& \mathrm{D}$, dos quais $50 \%$ desse valor deveriam ser direcionados a projetos cooperativos com instituições 
de pesquisa credenciadas pela ANP. Essa alteração feita pela ANP é anterior à Lei de Inovação, regulamentada em 2005.

Até 2005, essas articulações eram efetivadas através de termos de cooperação tecnológica, que possibilitavam à comunidade acadêmica a oportunidade de trabalhar em projetos reais com a indústria, viabilizando o aparelhamento de laboratórios e a capacitação do corpo de professores na aplicação prática de novas tecnologias. A preocupação em mobilizar competências complementares através de projetos cooperativos que possibilitassem uma "integração tecnológica" mais efetiva resultou no estabelecimento de 1.521 convênios e contratos com universidades e institutos de pesquisa com 120 instituições no período 2001-2005. A partir de 2005, a Petrobras vem procurando substituir o antigo modelo de gestão de contratos de cooperação com agentes externos vinculados a seus programas estratégicos por um novo modelo de gestão, baseado na estruturação de redes temáticas. Os núcleos de competência associados às redes temáticas estruturam-se a partir de quatro áreas que se desdobram numa série de temas vinculados a tecnologias estratégicas. ${ }^{15}$

Em função da implementação dessa nova sistemática de "integração tecnológica”, já se estruturaram 38 redes temáticas envolvendo 71 instituições em 19 estados da federação, bem como 7 núcleos regionais, com a função de atender demandas locais das diversas unidades da empresa. O programa de redes temáticas envolve um investimento de aproximadamente R $\$ 300$ milhôes/ano e cerca de 100 instituições no Brasil. Informações disponíveis apontam que a Petrobras investia em 2001 menos de $\mathrm{R} \$ 50$ milhōes em projetos de $\mathrm{P} \& \mathrm{D}$ feitos em parceria com as universidades. Em 2003, esse montante se elevou para mais de R $\$ 100$ milhões e, em 2006, a cifra ultrapassou os $\mathrm{R} \$ 350$ milhōes, devendo chegar a quase $\mathrm{R} \$ 400$ milhões em 2007 e em 2008. Considerando investimentos estimados em P\&D da ordem de $\mathrm{R} \$ 1,5$ bilhão em 2007, observa-se que quase um terço destes estariam vinculados a articulações com instituições de pesquisa brasileira.

15 As áreas temáticas e as respectivas tecnologias estratégicas são as seguintes: 1) exploração: geofísica aplicada, geoquímica, sedimentologia e estratigrafia, geotectônica; 2) produção: computação e visualização científica, gerenciamento de águas, materiais e controle de corrosão, revitalização de campos maduros, óleos Pesados, gerenciamento e simulação de reservatórios, modelagem e observação oceanográfica, estruturas submarinas, monitoração, controle e automação de poços; 3) abastecimento: asfalto, fluidodinâmica computacional aplicada ao refino, concretos e refratários, instrumentação, automação, controle e otimização de processos, combustíveis limpos, produtos e processos para o refino, catálise, desenvolvimento veicular, materiais aplicados ao refino, cadeia de suprimento, metrologia, tecnologia em dutos, construção naval; 4) gás, energia e desenvolvimento sustentável: nanotecnologia, hidrogênio: produção uso e armazenagem, bioprodutos, tecnologias do gás natural, mudanças climáticas, monitoramento ambiental marinho, conservação e recuperação de ecossistemas e remediação de áreas impactadas. 
A infraestrutura de C\&T associada ao APM é representada no lado direito da parte inferior da Figura 1. No caso do Rio de Janeiro, cumpre destacar as seguintes instituiçôes:

1) o Centro de Pesquisas da Petrobras - CENPES, que conta com mais de 1.600 técnicos e pesquisadores, é responsável pelo desenvolvimento de atividades de pesquisa e desenvolvimento $(\mathrm{P} \& \mathrm{D})$ da estatal, sendo responsável pelas principais inovações tecnológicas da empresa, sobretudo no segmento de exploração e produção de petróleo e gás, com registro de inúmeras patentes;

2) diversas instituições universitárias, como a Coordenação dos Programas de Pós-Graduação em Engenharia - COPPE, que realizou ao longo dos últimos 25 anos mais de 1.000 contratos de pesquisa para a Petrobras; a Pontifícia Universidade Católica do Rio de Janeiro - PUC-Rio, que desenvolve igualmente projetos de pesquisa para a Petrobras na área de E\&P (Silva, 2004:206).

Já a infraestrutura de ciência e tecnologia voltada para as atividades off-shore na BC estabelecida em Macaé expandiu-se consideravelmente nos anos 1990. Destacamse as seguintes instituições:

1) LENEP - Laboratório de Engenharia e Exploração de Petróleo da Universidade Estadual do Norte Fluminense (UENF) - desenvolvido em parceria com a Petrobras, que se constitui em um centro de pesquisa de excelência, oferecendo ainda cursos de pós-graduação em nível de mestrado e doutorado;

2) IMMT - Instituto Macaé de Metrologia e Tecnologia - desenvolvido pela Prefeitura Municipal com apoio do Instituto Nacional de Metrologia - INMETRO;

3) Projeto Bompetro - constituído através de um laboratório de geoprocessamento resultante de parceria com o Observatório Nacional, que desenvolve mapas digitalizados para o gerenciamento municipal e empresas interessadas;

4) NUPEM - Núcleo de Pesquisa Ecológica de Macaé - fruto de uma parceira entre a Petrobras e o Instituto de Biologia da Universidade Federal do Rio de Janeiro (UFRJ);

5) CEFET - Centro Federal de Educação Tecnológica - Campos - um dos principais responsáveis pela formação de mão de obra técnica para a indústria do petróleo desde a década de 1970 (Terra, 2003). 
As entrevistas realizadas com os agentes do APM revelaram que a infraestrutura de conhecimento que dá suporte às empresas do segmento off-shore tem contribuído para incrementar o processo de aprendizado e inovação no arranjo. Contudo, reconhece-se que tal infraestrutura ainda é deficiente sob vários aspectos, com destaque para a formação de mão de obra qualificada para a indústria.

\section{Política de subcontratação da Petrobras: impactos no processo de cooperação técnico-produtiva do aglomerado}

\subsection{Políticas de subcontratação da Petrobras: tendências gerais}

No âmbito internacional, observa-se que a sofisticação e a complexidade tecnológica crescente da atividade petrolífera aprofundaram a divisão do trabalho na cadeia de suprimento nesse setor, fazendo com que companhias de petróleo evoluíssem no sentido de uma organização mais desverticalizada, resultando no desengajamento de certas atividades, tais como a perfuração e a completação de poços. A crescente necessidade de externalização de determinadas atividades para fornecedores especializados por parte das operadoras decorre da grande heterogeneidade associada às bases de conhecimentos e competências envolvidas; ao mesmo tempo, a interrelação entre operadoras e seu núcleo de fornecedores especializados torna-se cada vez mais complexa.

Assim, a indústria petrolífera off-shore vem adotando novos procedimentos para a seleção e desempenho dos fornecedores de sistemas, componentes e serviços que integram os complexos projetos, envolvendo as atividades de exploração, desenvolvimento e produção. A recente dinâmica da indústria petrolífera internacional sofre a influência dos seguintes fatores:

1) da necessidade de as operadoras aumentarem a eficiência produtiva determinada, sobretudo pelo acirrado processo competitivo que se estabelece na referida indústria; e

2) da necessidade das majors em cumprirem exigências cada vez mais rígidas das autoridades ambientais, com relação a padrões de segurança relacionados ao meio ambiente. 
Dessa forma, as operadoras têm buscado concentrar suas atividades no planejamento, desenvolvimento, integração e fiscalização de projetos ao longo da cadeia de suprimento de componentes e serviços.

Em sintonia com as mudanças do mercado mundial de energia, a Petrobras vem procurando ampliar seu escopo de atuação para além das atividades envolvendo petróleo e gás, passando a se autodenominar como uma "empresa de energia". Nessa nova concepção, a estatal passou a investir na produção e comercialização de outras fontes de energia, como os biocombustíveis, investimentos em termoelétricas e na produção de energia eólica. A Petrobras, ao redefinir seu posicionamento estratégico nos mercados global e nacional de energia, intensificou seu processo de reestruturação produtiva a partir de 2002. Um dos desdobramentos desse processo foi a implementação da nova política de contratações da estatal. A reorganização dos procedimentos de contratação por parte da Petrobras vem determinando importantes mudanças nas relaçôes que a estatal estabelece com os fornecedores de bens e serviços ao longo de toda a cadeia produtiva. O novo sistema de contratação da Petrobras "é implementado com o objetivo de reduzir o número de contratos, evitar a participação de empresas que apresentem risco de falência, aumentar a segurança das operações, diminuir processos trabalhistas, elevar a qualificação profissional da massa contratada e garantir um resultado operacional eficaz" (Vasconcelos, 2002b:24).

Visando captar os impactos da evolução recente da política de subcontratação da Petrobras sobre o aglomerado, procurou-se realizar uma pesquisa qualitativa com as empresas instaladas na região. A metodologia utilizada para o desenvolvimento da pesquisa consistiu na utilização de dados oficiais, bem como em entrevistas e na aplicação de um questionário às empresas off-shore do APM. O questionário, composto de 49 perguntas, foi dividido em duas partes. Na primeira parte, as perguntas tiveram o propósito de avaliar a percepção dos entrevistados com vistas à infraestrutura física do aglomerado. Na segunda parte, as perguntas foram direcionadas no sentido de identificar questôes relativas à organização industrial, bem como as formas de cooperação, inovação tecnológica e fatores determinantes para a competitividade local do aglomerado. A aplicação do questionário consistiu na definição de uma amostra de 30 empresas off-shore, de pequeno, médio e grande portes. Além da Petrobras, foram selecionadas empresas prestadoras de serviços e empresas provedoras de insumos, definidas com base no cadastro da revista especializada $T \& N$ Petróleo e do cadastro de empresas da Federação das Indústrias do Estado do Rio de Janeiro (FIRJAN). Da amostra selecionada 18 
empresas ${ }^{16}$ participaram, e profissionais em cargos de direção de 12 delas, incluindo a Petrobras, responderam simultaneamente ao questionário e a perguntas afins realizadas pelos entrevistadores. Quatro empresas realizaram apenas entrevistas, sem a utilização de questionários. As entrevistas somadas às respostas do questionário possibilitaram uma visão ampliada das relações que se estabelece em Macaé, entre a Petrobras e demais operadoras, e destas com as prestadoras de serviços de grande, médio e pequeno porte. ${ }^{17}$ Deve-se destacar, ainda, a grande representatividade de empresas como a Petrobras, Slumberger e Transoceam dentre outras entrevistadas, cujo volume de transações e de faturamento se estima que supera $50 \%$ do conjunto do aglomerado. Particular atenção foi atribuída aos impactos decorrentes de mudanças recentes na política de contratação de empresas fornecedoras de bens e prestadoras de serviços pela Petrobras UN-BC.

O contexto no qual a pesquisa foi realizada (2004) refletia um processo de reajustamento da política de subcontratação da Petrobras. A ênfase na melhoria da seleção para contratação torna-se uma política global da estatal, definida para ser implantada por todas as suas unidades no país. Contudo, como a gestão é partilhada por regiōes administrativas, cada unidade de negócio moldou a sua própria política de contratação, de acordo com suas necessidades específicas. Vale destacar que, nesse processo, a Petrobras UN-BC absorve fortemente o impacto dessa nova padronização, pois é aquela que arregimenta o maior número de contratos na companhia. Nesse sentido, no final do ano de 2002, a Petrobras UN-BC tinha em carteira 593 contratos, em sua grande maioria na área de prestação de serviços.

O gerenciamento do grande volume de contratos passou a afetar a eficiência produtiva da Unidade (Vasconcelos, 2002b:25). A mudança no sistema de contratação da Petrobras UN-BC buscou aumentar a competitividade, a flexibilidade, possibilitando também a redução dos custos da estatal. Esaa reestruturação foi iniciada pelos serviços considerados prioritários, distribuídos em quatro grandes

16 As entrevistas somadas às respostas do questionário possibilitaram uma visão ampliada das relações que se estabelecem em Macaé entre a Petrobras e a demais operadoras e destas com as prestadoras de serviços de grande, médio e pequeno porte. Participaram das entrevistas estruturadas com respostas aos questionários as seguintes empresas do aglomerado: Petrobras UN-BC; SUPERQUIP - Representações Comerciais; Marine Operações de Robótica; Slumberger; MPE - Engenharia e Montagem de Gás e Óleo; Alphatec Soldagem e Caldeiraria; Polar Material Elétrico; Petroenge Petróleo Engenharia e Manutenção; Globomar Comércio Ltda.; Clariant Tratamento de Produtos Químicos; Q\&B Serviços Ltda. - Perfuração e Produção; Transocean; Associação Comercial e Industrial de Macaé (ACIM) e Grupo de Empresas Prestadoras de Serviços da Indústria de Petróleo e Afins (GEPES).

17 Embora se trate de uma amostra relativamente pequena, tendo em vista o número de empresas que atuam no aglomerado, procurou-se selecionar empresas e instituições com grande representatividade na indústria local offshore, de modo que se pudesse delinear as impressões destas sobre a dinâmica, competitividade e sustentabilidade da estrutura socioprodutiva local. 
famílias: manutenção, hotelaria, construção e montagem, e operação e manutenção de guindastes (Vasconcelos, 2002b:24-25). As principais mudanças alteraram a forma de selecionar e acompanhar o desempenho das prestadoras ${ }^{18}$ de serviços no que diz respeito aos aspectos trabalhistas, sociais, econômico-financeiros, técnicos, de segurança e meio ambiente. A medição do desempenho de empresas prestadoras de serviços e similares foi padronizada e adotou-se a padronização e avaliação dos contratos através de itens de controle idênticos.

Nesse contexto, o Boletim de Avaliação de Desempenho (BAD) opera como documento que habilita as empresas a ingressarem no quadro de fornecedores da estatal. Para tal, exige-se uma avaliação pelo menos regular por uma empresa de consultoria contratada, em que são auditados 10 requisitos legais, todos eliminatórios; 9 econômico-financeiros (alguns eliminatórios); 33 técnicos abrangentes e específicos; 25 aspectos de segurança, medicina e saúde ocupacional (SMS) ${ }^{19}$ (Vasconcelos, 2002b:26). O processo de seleção de fornecedores considera, além do preço, os fatores acima mencionados. Para a Petrobras, deixa de valer a política do "menor preço", a qual é substituída por uma política do "melhor preço", ${ }^{20}$ qual seja, o preço do produto ou serviço que viabiliza a condução do contrato, por parte do fornecedor, de maneira eficiente, nos prazos estabelecidos. Essa mudança foi um reflexo de problemas enfrentados pela Petrobras com alguns fornecedores, que reduziam seus preços em níveis particularmente baixos, mas se defrontavam com dificuldades para dar prosseguimento aos contratos, inclusive gerando entraves na área legal, na forma de ações contra a estatal. ${ }^{21}$

No APM a constituição de uma estrutura hierarquizada de prestadores de serviço sob a coordenação da Petrobras, envolvendo grandes e pequenas empresas, resulta em grande parte das mudanças verificadas na indústria off-shore internacional, em que a maior parte das operadoras reorganizou o processo de compras com especialização e centralização das atividades, envolvendo critérios cada vez mais rígidos para a seleção de fornecedores. Uma das questões fundamentais para se entender

18 Uma empresa especializada em consultoria, a Deloitte, foi contratada para auditar os critérios de seleção dos fornecedores de bens e serviços da Petrobras.

19 A sigla SMS - Segurança, Meio Ambiente e Saúde - relaciona-se à certificação conferida pela auditoria da Petrobras às empresas que desejam ser cadastradas em sua lista de fornecedores. As empresas que não conseguem passar pela auditoria recebem um relatório expondo as suas "não-conformidades". Se corrigirem as pendências, que devem ser reavaliadas em outra auditoria, são integradas na lista de fornecedores da Petrobras e podem assim participar dos processos licitatórios.

20 Para facilitar a avaliação do melhor preço, a Petrobras padronizou a Planilha de Orçamentação, em que se faz uma minuciosa previsão dos custos que incorrerão ao longo da duração do contrato (Vasconcelos, 2002b:26).

21 A Petrobras UN-BC enfrenta diversos processos trabalhistas oriundos de trabalhadores de outras empresas que prestam serviços nas dependências da estatal. 
a dinâmica de um aglomerado produtivo diz respeito às relaçôes que as empresas estabelecem entre si e como tais relaçōes estimulam a melhoria das competências tecnológicas, da tecnologia per se e dos produtos e serviços (Nadiv, 1995:13). Na análise que se segue, procura-se avançar na compreensão do modus operandi do aglomerado petrolífero de Macaé, articulando-o à política de subcontratação da Petrobras, em especial no que se refere à contratação de PMEs.

\subsection{Cooperação técnico-produtiva no APM e o papel das PMEs}

É notório o papel das PMEs na geração de emprego, renda e sustentabilidade socioeconômica de localidades e regiōes. Por outro lado, deve-se destacar que o elevado padrão tecnológico da indústria off-shore implica mudanças qualitativas importantes nos relacionamentos interindustriais envolvendo essas empresas. No âmbito específico do aglomerado de Macaé, as mudanças empreendidas na política de subcontratação da Petrobras afetaram a maioria das PMES que atuam no aglomerado. Tais mudanças determinaram a adoção de novas estratégias competitivas que se traduziram, por um lado, em fusões e aquisiçōes e, por outro, no reforço - enquanto estratégia de sobrevivência - dos vínculos de cooperação, sobretudo por parte das PMEs mais dinâmicas. No caso das grandes empresas off-shore, multinacionais em sua grande maioria, o ambiente em mutação tem induzido a realização de fusões. Empresas de variados portes passaram a se articular através de consórcios, de joint ventures e da aquisição de ações, buscando atender aos critérios de seleção definidos pela Petrobras, sobretudo àqueles relacionados aos aspectos econômico-financeiros. Destacam-se alguns exemplos do processo de fusóes que vêm ocorrendo no mercado off-shore de Macaé - especialmente a partir do novo sistema de contratações adotado pela Petrobras, a saber: a empresa Q\&B integrou-se com Off-Shore Crane; a Santos Barbosa com Would Group; a BSM com Sparows Off-Shore Services e a AC Engenharia com a Promon (Vasconcelos, 2002a:27).

O novo modelo de contratação da Petrobras foi implantado em um período de franca expansão do aglomerado petrolífero de Macaé, afetando as empresas de uma forma geral. Porém o impacto nas firmas de pequeno e médio porte se fez sentir com maior ímpeto, dadas as fragilidades que tipificam as PMEs, tais como o reduzido capital para investimentos, o baixo nível de organização administrativa e a mão de obra com pouca qualificação. A nova política de contratação e subcontratação da Petrobras UN-BC passou a atingir as PMEs em pelo menos três pontos: 
1) no princípio geral do novo formato, pois, quando o sistema proposto passar a funcionar plenamente, com a generalização de contratos de cinco anos e a intermediação de EPCistas, as PMEs praticamente deixarão de prestar serviços diretamente à Petrobras;

2) no critério econômico-financeiro - um dos critérios determinantes para a participação no processo de licitação da estatal -, que é propositalmente elevado, o que praticamente exclui as PMEs dos processos licitatórios de maior vulto;

3) em critérios mais rigorosos relacionados à qualificação da mão de obra, certificações de qualidade envolvendo produtos e serviços, e ao atendimento a padrões de segurança, meio ambiente e saúde ocupacional, os quais tendem a impor às PMEs um rápido processo de reestruturação produtiva que, em geral, é muito oneroso.

com efeito, a necessidade de recursos adicionais para atender aos novos critérios definidos pela Petrobras dá-se pari passu ao aumento das restrições para a participação direta das PMEs como fornecedores da estatal.

Nesse contexto, algumas questões captadas nas entrevistas qualitativas realizadas são ilustrativas. Em particular, a certificação coloca-se como uma das principais exigências do mercado off-shore, com reflexos diretos na estrutura de custos das empresas. A nova política de contratação da Petrobras exige a certificação e a qualificação da mão de obra contratada, especialmente nas denominadas "funções críticas", a saber: serviços prestados à empresa nas áreas de manutenção, hotelaria, O\&M, operação de guindastes; construção e montagem (Tabela 3). Todo esse processo visa atingir os seguintes objetivos:

1) reduzir o número de contratos e garantir a eficiência produtiva da empresa;

2) minimizar riscos de acidentes;

3) reduzir o não-cumprimento de contratos por parte dos fornecedores de bens e serviços; e

4) reduzir as ações trabalhistas contra a empresa (Vasconcelos, 2002b:26).

no sentido de garantir a eficiência da mão de obra subcontratada, a Petrobras, em muitos casos, exige a certificação profissional do trabalhador terceirizado, além de submetê-lo a provas teóricas e práticas em situações que simulem operações off-shore a que esse profissional é submetido. 
TABELA 3

Petrobras - Meta de redução do número de contratos na UN-BC até 2007

Redução do número de contratos da UN-BC

Família de atividades

Manutenção

Hotelaria

O\&M guindastes

Construção e montagem

Total

Fonte: Vasconcelos (2002b).
Número de contratos atual

43

66

26

86

221

Número de contratos futuros

9

10

10

10

39

Outra mudança importante diz respeito à estrutura dos contratos, que passaram a ser formatados com base em dois parâmetros:

1) uma abrangência mais ampla, isto é, contemplando um leque maior de atividades, de modo a que todos os serviços similares em um determinado projeto passem a fazer parte de um mesmo pacote - esses contratos mais amplos são conhecidos como "supercontratos";

2) o alongamento dos prazos de duração dos contratos da UN-BC, que dispõem de um tempo médio de cinco anos, podendo ser renovados.

de acordo com a gerência de operaçôes da Petrobras UN-BC, o novo sistema de contrataçôes deveria ser implantado de forma gradual. Assim, até que as empresas das quatro famílias de serviços selecionados (Tabela 3) começassem a operar através de contratos de cinco anos, a estatal operaria com contratos transitórios, entre dois e três anos, de modo que os contratos de cinco anos iniciassem juntamente com a implementação integral dos novos critérios. ${ }^{22}$

Se, por um lado, as novas exigências tenderam a aumentar a eficiência produtiva da indústria off-shore em Macaé, abrangendo, inclusive, a melhoria das condições 
salariais, de saúde ocupacional e de segurança dos trabalhadores, por outro, criaram uma grande incerteza no mercado no que diz respeito à forma de inserção das PMEs na nova estrutura organizacional que se moldou no aglomerado. Nesse sentido, a consolidação do novo modelo tendeu a produzir uma maior verticalização ${ }^{23}$ na cadeia de serviços da indústria off-shore, em Macaé, e a aumentar os ganhos relativos das grandes empresas em detrimento das PMEs.

$\mathrm{Na}$ estruturação do novo modelo, era esperado que as PMEs pudessem qualificar-se de modo a atuarem como subcontratadas de EPCistas, ou que atingissem padrōes produtivos relativamente elevados para se tornarem provedoras diretas de bens e serviços da estatal. Entretanto, essas possibilidades tendem a ser limitadas em função das seguintes questôes:

1) a persistência de restriçõos financeiras para a capacitação das PMEs do aglomerado;

2) a necessidade de se construir novos padrões de relacionamentos produtivos entre PMEs e grandes empresas - sejam elas EPCistas nacionais da área de engenharia e/ou empresas multinacionais especializadas no segmento off-shoreque tendem a se converter nas principais fornecedoras diretas de bens e serviços com a Petrobras UN-BC; e

3) a magnitude dos impactos que tais mudanças acarretariam sobre a dinâmica do aglomerado, especialmente no que diz respeito à renda, ao emprego e, principalmente, à sua sustentabilidade de longo prazo.

Assim, decorrem desse processo dois efeitos negativos sobre as PMEs integradas ao aglomerado produtivo de Macaé:

1) uma parte significativa das PMEs de menor nível de capacitação tecnológica tende a diminuir os vínculos produtivos com o aglomerado, visto que não consegue atingir os requisitos mínimos de qualidade, produção, capital, qualificação da mão de obra, dentre outras exigências, definidos pela Petrobras como empresa-âncora;

2) a precariedade das condições de infraestruturas e de instituições de apoio às PMEs e as mudanças na política de contratação da Petrobras - que reforça a verticalização da estrutura produtiva - tendem a promover a "descapilarização" de uma rede de empresas com potencial de estruturação em um setor de elevada 
densidade tecnológica, podendo gerar prejuízos concretos para a formação de capitais intangíveis, para a disseminação de uma cultura inovadora e para a diversificação produtiva do aglomerado.

$\mathrm{Na}$ ausência de regulamentações mais efetivas que garantam a participação das empresas em bases competitivas no mercado off-shore de Macaé, algumas estratégias têm sido adotadas pelas PMEs para fazer face às mudanças determinadas pelo modelo de contratação da Petrobras. Com efeito, é possível observar o desenvolvimento de mecanismos de coordenação que contribuem para uma maior estabilidade do ambiente microeconômico, minimizando incertezas. No que tange às principais estratégias utilizadas pelas PMEs, no sentido de garantir-lhes a permanência no mercado, destacam-se:

1) a diversificação de suas atividades produtivas, contemplando principalmente aquelas que requerem menor investimento, como, por exemplo, a atuação no segmento de representação comercial (inclusive como importadores de componentes fabricados no exterior, em especial na China);

2) a articulação entre PMEs, inclusive por meio de fusōes, no sentido de atenderem aos requisitos mínimos econômicos, financeiros, tecnológicos e de SMS definidos pela Petrobras, tendo em vista a participação nas licitações da estatal, ou para poderem atuar no mercado como subcontratadas;

3) a realização de investimentos na qualificação da mão de obra e na padronização de procedimentos técnicos para obtenção das certificaçôes exigidas pelo mercado;

4) organização de instituições de apoio às suas atividades como redes de fornecedores, sindicatos patronais, consórcios para compra de insumos etc.

Visando contrapor-se à defasagem em termos de capacitação tecnológica em relação às grandes empresas, torna-se particularmente importante para as PMEs o desenvolvimento de ações coletivas, com destaque para a constituição de consórcios para a compra de máquinas, equipamentos e matérias-primas; a participação em feiras tecnológicas na área off-shore; e a realização de parcerias interfirmas, visando à adequação em relação à escala necessária para a participação de concorrências envolvendo projetos de maior vulto com a Petrobras, aos EPCistas e às demais operadoras contratantes na BC. Buscando elevar a eficiência do novo processo de contratação e subcontratação, a Petrobras procurou, a partir de 2002, implementar 
um conjunto de ações de suporte à implantação da nova política. Dentre essas ações, é possível destacar:

1) uma ampla divulgação nos executivos municipais e empresas contratadas, sobre as razōes da mudança e etapas do processo;

2) a montagem de oito centros de qualificação e certificação em Macaé - mobilizando instituiçóes como o SENAI e o CEFET - voltados para atender as empresas prestadoras de serviços nas funções críticas identificadas pela Petrobras, especialmente nas áreas de caldeiraria, eletricidade, instrumentação e mecânica;

3) a realização de parcerias com o poder público para a implantação de programas visando à melhoria da escolaridade;

4) a aceitação da subcontratação de serviços considerados não-essenciais;

5) a aceitação, por dois anos, de consórcios oficialmente estruturados, possibilitando, ainda que temporariamente, a inserção de médias empresas no fornecimento direto à Petrobras;

6) a ampliação de incentivos ao programa QualiRio. ${ }^{24}$

no entanto, deve-se destacar que, apesar das ações empreendidas pela Petrobras, os resultados efetivos foram relativamente modestos. De acordo com a maior parte das PMEs entrevistadas, as restriçōes financeiras, tecnológicas, de escala de produção, dentre outras, as impedem de atenderem grande parte dos requisitos impostos pela estatal.

Do ponto de vista microeconômico, observa-se o desenvolvimento e fortalecimento de instituições voltadas para a melhoria do processo de coordenação dos agentes do APM. Como exemplo, é possível citar a constituição em Macaé do Grupo de Empresas Prestadoras de Serviços na Indústria de Petróleo e Gás - GEPS, a partir da percepção, por parte das PMEs, dos impactos potencialmente negativos gerados pela reorientação da política de contratação da Petrobras. Essas instituições têm contribuído para a definição de um sistema de governança que permita às PMEs minimizar os efeitos da reestruturação produtiva decorrente da reorientação da política de contrataçôes da Petrobras. No que tange às instituições que dão suporte às atividades off-shore na bacia de Campos, é importante destacar também a atuação 240 programa QualiRio tem por objetivo a qualificação de PMEs para atenderem os padrões de qualidade e de conformidade industrial no estado do Rio de Janeiro. 
da Organização Nacional da Indústria do Petróleo (ONIP), que tem desempenhado relevante papel nas empresas que atendem à indústria de petróleo e gás, com destaque para as PMEs. Nesse sentido, quase $40 \%$ do Cadastro de Fornecedores de Bens e Serviços da ONIP é formado por empresas de até cem funcionários, com faturamento anual de até R \$ 1,2 milhão (Macedo, 2003:40). Pertencer ao cadastro ${ }^{25} \mathrm{da}$ ONIP possibilita tornar-se um fornecedor com credibilidade no mercado. Para isso, é preciso que o empresário realize cursos de capacitação de modo a estar preparado a enfrentar as inúmeras exigências do mercado off-shore. Com esse intuito foi lançado em 2001 o programa Competitividade é a Nossa Plataforma pelo sistema SEBRAE, em parceria com a ONIP e o Ministério da Ciência e Tecnologia. Destacam-se também cursos de capacitação, que, a partir de 2002, se integram ao Programa de Capacitação de Fornecedores da Cadeia Produtiva de Petróleo e Gás, ${ }^{26}$ montado a partir de articulação entre o SEBRAE-RJ e a Prefeitura de Campos, o qual se iniciou com aulas de capacitação para 13 empresas. Em Macaé, o curso foi introduzido no mesmo período com a participação inicial de 15 empresas nas dependências da Associação Comercial e Industrial de Macaé - ACIM (Silva, 2004).

A partir dos resultados de pesquisa encomendada pelo SEBRAE à Fundação COPPETEC da UFRJ, integrado às atividades da Câmara de Desenvolvimento de Macaé, estruturou-se um projeto mais amplo do SEBRAE, voltado para a formação de um "arranjo produtivo local" de petróleo e gás, com base em Macaé (Macedo, 2003:41). Ao final de 2003, foi lançada a Rede de Empresas do Setor de Petróleo da Bacia de Campos - REDEPETRO - BC. A REDEPETRO-BC surge como resultado de uma parceria entre a Secretaria de Indústria e Comércio da Prefeitura de Macaé e o SEBRAE-RJ, sendo operacionalizada pelo Grupo de Produção Integrada GPICOPPE \& EP-UFRJ, além de uma equipe de colaboradores da região da bacia de Campos, contando ainda com o apoio da Petrobras UN-BC, além da Câmara de Desenvolvimento de Macaé. O projeto tinha por objetivo estruturar uma rede de pequenas e médias empresas off-shore nos municípios da bacia de Campos, de modo a garantir a competitividade delas em um cenário de mudanças radicais - como observado no aglomerado petrolífero de Macaé - que vinham afetando negativamente as firmas menores (ver Figura 1, Instituições de apoio).

\footnotetext{
25 Trata-se de um catálogo virtual disponível na home page da ONIP, que reúne empresas nacionais e estrangeiras qualificadas para atender às demandas da indústria petrolífera no país.

26 O programa utiliza um sistema integrado de gestão empresarial com ênfase nos indicadores de qualidade, meio ambiente, segurança no trabalho e saúde ocupacional. As PMEs que necessitam de apoio tecnológico são encaminhadas ao PATME (Programa de Apoio Tecnológico às Microempresas), que conta com 70\% de recursos financeiros do SEBRAE.
} 
Os principais atores desse arranjo compreendiam empresas fornecedoras de bens e serviços, empresas operadoras (em particular a Petrobras), diversas instâncias de governos, instituições de ensino e pesquisa e instituições de apoio em geral, com destaque para o SEBRAE-RJ, a FIRJAN-SENAI, as Associações Comerciais e Industriais e a ONIP. O número de empresas integradas à rede totalizava 144 empresas em 2005, destacando-se um grupo executivo composto por 16 empresas e um grupo de apoio formado por 12 instituições tecnológicas e empresariais. O objetivo era tornar essa rede uma referência nacional em termos de padróes de relacionamentos para troca de informaçóes, desenvolvimento produtivo e tecnológico e identificação de demandas para a cadeia produtiva do petróleo e gás natural. Nesse sentido, a articulação das PMEs por meio de instituições como a REDEPETRO-BC tem demonstrado ser um mecanismo importante, mas ainda insuficiente para minorar o problema de assimetria de poder existente no APM.

\section{Considerações finais}

Tem sido prática comum em algumas regiōes e localidades desenvolvidas onde operam indústrias off-shore o emprego de regulamentaçōes e a criação de mecanismos de coordenação por parte do poder público, com intuito de garantir a participação de PMEs sob bases competitivas no mercado. Nesse sentido, ressalta-se que o desenvolvimento de sistemas produtivos locais baseados na indústria off-shore de países como a Noruega, Canadá e Reino Unido ocorreram à custa de pesadas regulamentaçôes e de incentivos diversos, objetivando promover a indústria local (Hatakenaka et al., 2006; Macedo, 2003). Nesses sistemas, evidencia-se respectivamente uma forte preocupação quanto ao estabelecimento de modelos de governança que preservem a participação das PMEs, sob bases competitivas, de maneira a garantir a sustentabilidade dos sistemas produtivos locais (Silva, 2004).

Quanto ao processo de governança, evidências levantadas nas empresas do aglomerado produtivo de Macaé revelaram que a participação do poder público enquanto agente no processo de coordenação coletiva ainda é modesta. Nesse sentido, vale ressaltar a precariedade das regulamentaçôes governamentais relativas à atuação de PMEs no mercado off-shore regional/local, que lhes permitissem atuar em bases mais competitivas nesse mercado, vis-à-vis o poder exercido pelas grandes operadoras, em particular pela Petrobras. Em especial, observa-se que, no caso brasileiro, o recente modelo de regulação da indústria petrolífera enfatiza o plano nacional, deixando um vácuo nas esferas regional/local. No plano nacional merece 
destaque o Programa de Mobilização da Indústria Nacional de Petróleo e Gás Natural (PROMINP) e regulamentações, por parte da ANP, que definem índices mínimos de nacionalização relacionados à produção de bens e serviços voltados para a indústria. Após uma relativa desmobilização dos programas de capacitação de fornecedores no fim da década de 1990, o quadro se modifica com a mudança de governo em 2002 e a criação do PROMINP em 2003. Esse programa surge com o objetivo de maximizar a participação da indústria nacional de bens e serviços, em bases competitivas e sustentáveis, na implantação de projetos de óleo e gás no Brasil e no exterior, convertendo a produção de petróleo e gás natural, transporte marítimo e dutoviário, refino e distribuição de derivados em oportunidades de crescimento para a indústria nacional de bens e serviços. Nesse sentido, procura integrar açōes vinculadas a outros programas de capacitação existentes e os esforços de qualificação da mão de obra numa lógica geral de reforço de índices de nacionalização no suprimento de bens e serviços em condiçōes competitivas. Com o advento do PROMINP, foi reforçada a preocupação com o desenvolvimento de fornecedores locais, através da identificação de nichos para substituição da importação de itens (equipamentos, componentes etc.), em que o fornecimento por parte de empresas nacionais apresenta benefícios potenciais.

Mais recentemente, a atuação descentralizada da Petrobras, através de suas diversas unidades operacionais, tem estimulado também a implementação de ações orientada para a territorialização dos esforços de capacitação comandados pela empresa, através da mobilização de núcleos regionais de capacitação, visando estimular a consolidação dos arranjos territoriais de fornecedores no setor de petróleo e gás. A consolidação desses núcleos foi acelerada a partir do ano 2000, quando o SEBRAE Nacional assinou um acordo de cooperação com a ONIP, o Ministério do Desenvolvimento e Comércio Exterior (MDIC) e o Ministério da Ciência e Tecnologia (MCT), o qual resultou, em 2002, na consolidação de um programa nacional, com núcleos instalados em 12 estados, para qualificação de micro e pequenas empresas, tendo como objetivo a inserção competitiva delas no mercado do petróleo. ${ }^{27}$ Cada projeto visava capacitar micro e pequenas empresas e induzir a implementação de um fórum para melhoria da competitividade da cadeia produtiva local. Como reflexo, foi criado em 2003 pelo governo federal o Programa da Cadeia Produtiva

27 Esses núcleos, a princípio, deveriam direcionar-se para determinados setores, a saber: metal-mecânico (usinagem, caldeiraria, soldagem); eletroeletrônico (motores, circuitos e painéis elétricos); hidráulico (sistemas, bombas, válvulas); pneumático (sistemas, bombas, válvulas); manutenção industrial; projeto de engenharia, construção e montagem; refrigeração (manutenção, projeto, montagem); químico e tratamento de água; equipamentos de segurança; pintura; transporte e consultoria. 
do Petróleo e Gás, que passou a integrar a carteira de projetos do PROMINP, Em outubro de 2004, foi assinado um convênio entre o SEBRAE Nacional e a Petrobras para inserção competitiva e sustentável de micro e pequenas empresas nessa cadeia. Esse convênio definiu com principais focos estratégicos os seguintes temas: a capacitação de micro e pequenas empresas, a formação e a consolidação de redes de cooperação competitiva de empresas petrolíferas e fornecedores locais, a realização de diagnóstico da capacitação de fornecedores, a elaboração e implementação de plano de desenvolvimento participativo para a cadeia produtiva, a sensibilização e mobilização de grandes fornecedores para o engajamento de PMEs como subfornecedoras locais, e a interação com outras redes de cooperação competitiva para a troca de experiências e promoção de negócios.

Um dos desdobramentos desse processo foi a implementação de uma nova política de contrataçóes, dotada de maior flexibilidade, para que cada unidade da estatal pudesse ajustá-la às idiossincrasias regionais/locais. No caso específico da Petrobras UN-BC, dado o caráter estratégico dessa província petrolífera, o formato da política de contratações adotado teve por objetivo principal a drástica redução do número de contratos. Além disso, o novo modelo previa critérios mais rígidos de contratação em aspectos trabalhistas, sociais, econômico-financeiros, técnicos, de segurança e de meio ambiente. A implantação da nova política, a partir de 2003, resultou em um forte processo de reestruturação produtiva no APM. Verificou-se então a ocorrência de fusōes, incorporações, alianças estratégicas, bem como a saída de muitas empresas do mercado, sobretudo PMEs, reforçando a tendência natural de concentração da indústria.

Nesse sentido, o quadro atual é um reflexo de múltiplas tendências. Apesar da atual política de subcontratação da Petrobras indicar a aceleração do processo de concentração industrial, com impactos potencialmente mais drásticos sobre as PMEs, também se observa uma tendência à intensificação da cooperação técnicoprodutiva, seja através das fusóes que ocorreram no aglomerado, seja por meio de uma maior articulação das PMEs através da formação de consórcios e redes de cooperação. De fato, uma das estratégias adotadas pelas PMEs para atender os novos parâmetros definidos pela Petrobras foi a intensificação da cooperação produtiva e tecnológica. As ações coletivas desenvolvidas pela REDEPETRO-BC parecem indicar, por um lado, uma reação das PMEs à atual política de contratação da Petrobras, no sentido de se tornarem mais competitivas para permanecerem no mercado, e, por outro, o ímpeto delas no sentido de arrefecer a acentuada assimetria existente no aglomerado. 
Apesar de modestos, é possível verificar avanços tanto no processo de governança como nos investimentos em infraestrutura física e do conhecimento no APM, os últimos impulsionados, sobretudo, pelos vultosos recursos oriundos dos royalties petrolíferos, auferidos pelo município de Macaé e pelo estado do Rio de Janeiro. No entanto, cumpre ressaltar que, apesar do expressivo potencial da bacia de Campos, os recursos petrolíferos desta são finitos, podendo-se observar uma tendência ao aumento da exploração de petróleo em bacias sedimentares adjacentes com potencial promissor (bacias de Santos e do Espírito Santo). Nesse sentido, é possível que o estímulo à localização de empresas atuantes no segmento off-shore no APM por questôes de facilidade logística possa ser, em parte, carreado para outras localidades. Esse processo pode ser acelerado em função da fragilidade do processo de governança, da persistência de desigualdades sociais e econômicas, da precariedade dos investimentos em infraestrutura urbana e das limitaçōes da base de conhecimentos relacionada à infraestrutura de C\&T local, características típicas de localidades de baixo desenvolvimento ainda presentes no APM.

\section{Referências bibliográficas}

Agência Nacional do Petróleo - ANP. Anuário estatístico de 2006, 2007. Disponível em <http:// www.ANP.gov.br/conheca/anuario_2006.asp>. Acesso em 21 de agosto de 2007.

Albagli, S.; Britto J. Glossário de arranjos e sistemas produtivos e inovativos locais. Arranjos produtivos locais - Uma nova estratégia de ação para o SEBRAE - Rede de Pesquisa em Sistemas Produtivos e Inovativos Locais. Instituto de Economia da Universidade Federal do Rio de Janeiro, out. 2003. Disponível em <www.ie.UFRJ.br/redesist>. Acesso em 4 de março de 2007.

Alveal, C.; Pinto Jr., H. "A cooperação inter-firmas na indústria petrolífera mundial", in Anais 24 Reunião da ANPEC, Campinas, 1996.

ANP - Agência Nacional do Petróleo. "Avaliação da competitividade do fornecedor nacional com relação aos principais bens e serviços", mimeo., maio, 1999. Disponível em $<$ http://www.ANP.gov.br/brasil-rounds/round1/Docs/compet.pdf> Acesso em agosto de 2006. 
Anuário estatístico do estado do Rio de Janeiro. Centro de Informaçōes e Dados do Estado do Rio de Janeiro - CIDE, 2000, 2001, 2002, 2003, 2004.

Azevedo, J.S.G "Petrobras no Rio de Janeiro", palestra proferida na Associação Comercial do Rio de Janeiro, 31/10/2006.

Bell, R.M.; Oldham, C.H.G. "Oil companies and the implementation of technical change in off shore operations: experience in development drilling and the design and operation of production facilities in the North sea”, SPRU - Sussex University: Report, n.2, abr., 1988.

Borges, M.; Campolina, C.; Borges, F.; Crocco, M.A.; Camargo, F. "O arranjo produtivo da rede Fiat de fornecedores. Estudos empíricos”, Nota Técnica, BNDES, FINEP, n. $15,2003$.

Britto, J. "Características estruturais e modus operandi das redes de firmas em condiçôes de diversidade tecnológica”, Tese de Doutorado em Economia, IE-UFRJ, 1999.

Castro, A. (coord.) "Impactos sociais do desenvolvimento da atividade de exploração e produção de petróleo nas regiōes das baixadas litorâneas e do norte fluminense. Projeto CTPETRO: tendências tecnológicas”, Nota Técnica, Rio de Janeiro, n.13, 2003.

Cooke, P. "Origins of the concept", in Braczyk, H.; Cooke, P.; Heidenreich, M. (org.), Regional innovation systems, Londres: UCL Press, p.2-25, 1998.

Dantas, A. "Capacitação tecnológica de fornecedores em redes de firmas: o caso da indústria do petróleo off-shore no Brasil”, Tese de Doutorado, IE-UFRJ, 1999

Dantas, E.; Bell, M. "Latecomer firms and the development of knowledge networks: the case of Petrobras in Brazil". Paper to be presented at the SPRU 40th Anniversary Conference on The Future of Science, Technology and Innovation Policy, Brighton, 11-13 set., 2006.

Etzkowitz, H.; Leydesdorff, L. "The dynamics of innovation: from national systems and 'mode 2' to a triple helix of university-industry-government relations", Research Policy, 29, p.109-123, 2000.

Florida, R. "Calibrating the learning regions", in Mothe, J.; Paquet, J. (org.), Local and regional systems of innovation, economics of science, technology and innovation, Massachusetts: Kluwer Academic Publisher, v.14, 1998.

Freeman, C. "Network of innovators: a synthesis of research issues", Research Policy, 20, p.499-514, 1991. 
Furtado, A. (coord.) "Política de compras da indústria do petróleo e gás natural e a capacitação de fornecedores no Brasil: o mercado de equipamentos para o desenvolvimento dos campos marítimos. Projeto CTPETRO: tendências tecnológicas”, Nota Técnica, Campinas: IG-UNICAMP, n.5, 2003.

Hatakenaka, S.; Westnes, P.; Gjelsvik, M.; Lester, R. "From 'black gold' to 'human gold': a comparative case study of the transition from a resource-based to a knowledge economy in Stavanger and Aberdeen", MIT Local Innovation Systems Working Paper, 06-002, 15 jul., 2006.

Instituto Brasileiro de Geografia e Estatística - IBGE. Anuário estatistico do Brasil 1995-2000.

Lastres, M.H.; Cassiolato, J.E. Novas políticas na era do conhecimento: o foco em arranjos produtivos e inovativos locais. RedeSist: IE-UFRJ, 2003a. Disponível em <www.ie.UFRJ. br/redesist>. Acesso em julho de 2003.

System of Innovation and development From a South American Perspective: A Contribution to Globelics. RedeSist: IE-UFRJ, 2003b. Disponível em <www.ie.UFRJ. br/redesist>. Acesso em julho de 2003.

Políticas para promoção de arranjos produtivos e inovativos locais de micro e pequenas empresas: conceitos, vantagens e restriçôes e equivocos usuais. RedeSist: IE-UFRJ, 2003c. Disponível em <www.ie.UFRJ.br/redesist>. Acesso em julho de 2003.

Lemos, M.; Diniz, C.; Santos, F.; Afonso, M.; Camargo, O. "O arranjo produtivo da rede Fiat de fornecedores. Projeto de Pesquisa Arranjos e Sistemas Produtivos e Inovativos Locais e as Novas Políticas de Desenvolvimento Industrial e Tecnológico. Estudos empíricos", Nota Técnica, IE-UFRJ, RedeSist, IE-UFRJ, n.15, 2000. Disponível em <www.ie.UFRJ.br/redesist>. Acesso em julho de 2003.

Macedo, R. "Reforma tributária pode definir rumos de investimentos nas atividades petrolíferas no litoral fluminense", Revista Macaé Offshore, Macaé, ano 3, p.152, nov.-dez., 2003.

Markusen, A. "Four structures for second tier citie", in Markusem, A.; Lee, Y.; Digiovanna, S. (eds.), Second teir cities: rapid growth beyond the metropolis, Minneapolis: University of Minnesota Press, 1999.

Mothe, J.; Paquet, G. "Local and regional systems of innovation as learning socio-economies”, in Mothe, J.; Paquet, G. (eds.), Local and regional systems of innovation, Boston: Kluwer Academic Publishers USA, 1998. 
Nadiv, K. Industrial clusters and networks: case studies of SME growth and innovation - Small enterprises medium programme. Vienna: The United Nations Industrial Organization UNIDO, 1995. Disponível em <http://www.unido.org/index.php?id=o51261>. Acesso em 20 de junho de 2006.

Nelson, R. National innovation systems: a comparative analysis, Nova York: Oxford University Press, 1993.

Organização Nacional da Indústria de Petróleo - ONIP. Disponível em <http://www.onip. org.br/index.asp>. Acesso em julho de 2003.

Petrobras. A evolução da produção na bacia de Campos. Minisite Águas Profundas, PROCAP 3000, 2006. Disponível em <http://www2.petrobras.com.br/portal/Petrobras.htm>. Acesso em 2 de setembro de 2003 e 2 de novembro de 2006.

Ramos, J. "Una estrategia de desarrollo a partir de complejos productivos en torno a los recursos narurales", Revista de la CEPAL, n.66, dez., 1999.

REDEPETRO-BC. Relatório preliminar sobre a rede de empresas off-shore que atende à bacia de Campos, Macaé: SEBRAE, 2003.

Relatório Anual de Informaçōes Sociais - RAIS 2005. Ministério do Trabalho e Emprego. Disponível em <http://www.rais.gov.br/>. Acesso em janeiro de 2007.

Saxenian, A. "Regional systems of innovation and the blurred firm", in Mothe, J.; Paquet, G. (orgs.), Local and regional systems of innovation, Kluwer Academic Publishers USA, 1998.

Secretaria de Fazenda de Macaé. Caderno Cidadão, segundo semestre, 2003.

Silva, R.C.R. "A indústria petrolífera em Macaé: caracterização e potencialidades do sistema produtivo local", Tese de Doutorado em Engenharia de Produção, Laboratório de Engenharia de Produção - CCT, Universidade Estadual do Norte Fluminense Darcy Ribeiro, mimeo., 2004.

Suzigan, W., Furtado, J.; Garcia, R.; Sampaio, S. "Aglomerados industriais no estado de São Paulo", texto apresentado no Seminário do Curso de Pós-Graduação em Economia do CEDEPLAR, UFMG, 2001. Disponível em <http://www.cedeplar.ufmg.br/economia/ seminarios.htm>. Acesso em 25 de janeiro de 2003.

Terra, D. "A formação de um cluster petrolífero nos municípios da bacia de Campos", in Piquet, R. (org.), Petróleo royalties e regiāo, Rio de Janeiro: Garamond, p.287-307, 2003. 
T\&N Petróleo. "Facilidades e logística no setor de óleo e gás no Brasil”, T\&N Petróleo, Rio de Janeiro, Benício Biz Editores Associados, n.18, encarte, 2001.

Vasconcelos, F. "Boa saúde financeira”, Revista Macaé Offshore, Macaé, n.2, jul., 2002a.

"Desempenho a toda prova: nova política de contratação da Petrobras mexe com as economias local e nacional”, Revista Macaé Offshore, Macaé, ano II, n.9, nov.dez., 2002b.

"Maior suporte à bacia de Campos", Revista Macaé Offshore, Macaé, ano III, n.14, set.-out., 2003.

ENDEREÇO PARA CORRESPONDENCIA:

Roberto Rosendo - rosendo@uenf.br

Universidade Estadual do Norte Fluminense Darcy Ribeiro

Centro de Ciências do Homem (CCH)

Laboratório de Estudos da Sociedade Civil e do Estado (LESCE)

Avenida Alberto Lamego, 2.000, Horto

28015-620 - Campos dos Goytacazes (RJ)

Jorge Britto - jbrit@terra.com.br

Universidade Federal Fluminense

Rua Tiradentes, 17, Ingá

24210-510 - Niterói (RJ)

Fone: (21) 2629-9714 